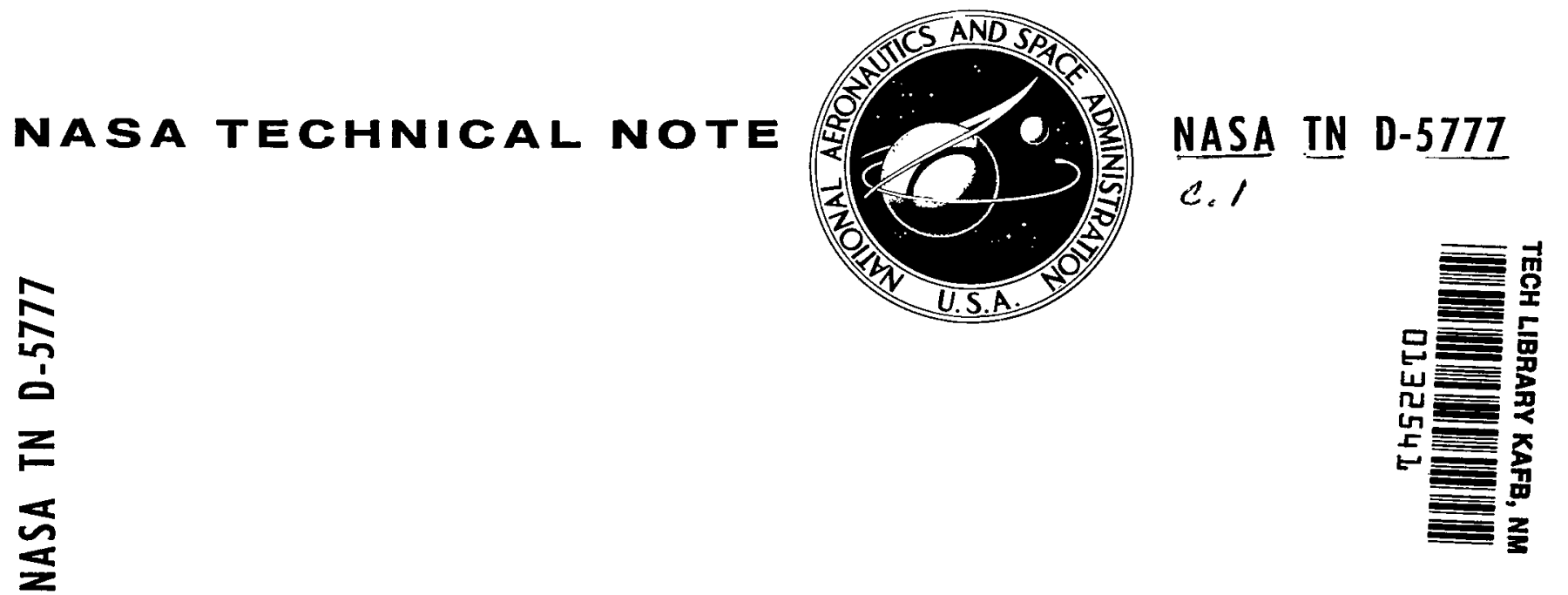

IOAN COPT: RETURA TO AFTL (TILOL) KIRTIAND AIB, N MERS

\title{
PHYSICAL ADSORPTION OF
}

NITROGEN GAS ON THE POLISHED

SURFACE OF 347 STAINLESS STEEL

\section{AT VERY LOW PRESSURES}

by R. A. Outlaw

Langley Research Center

Hampton, Va. 23365

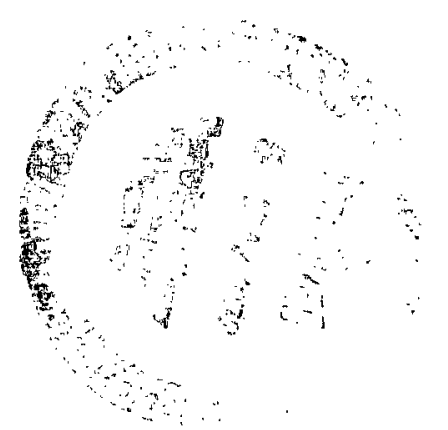

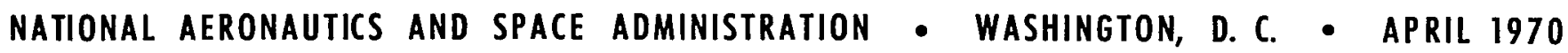


1. Report No.

NASA TN D -5777

4. Title and Subtitle

PHYSICAL ADSORPTION OF NITROGEN GAS ON THE POLISHED SURFACE OF 347 STAINLESS STEEL AT VERY LOW PRESSURES

7. Author(s)

R. A. Outlaw

9. Performing Organization Name and Address

NASA Langley Research Center

Hampton, Va. 23365

12. Sponsoring Agency Name and Address

National Aeronautics and Space Administration

Washington, D.C. 20546

15. Supplementary Notes

The information presented herein was included in a thesis offered in partial fulfill-

ment of the requirements for the degree of Master of Science, Virginia Polytechnic Institute, Blacksburg, Virginia, January 1969.

16. Abstract

A combined study of surface characterization and physical adsorption was performed for a material commonly used in vacuum instrumentation and hardware, namely, stainless steel. The characterization of the surface was accomplished by topography and chemical composition studies. Following this study, physical adsorption measurements of nitrogen gas on polished 347 stainless steel in the pressure range from $1 \times 10^{-9}$ to $1 \times 10^{-7}$ torr were made. Isotherms were plotted for test temperatures of $87.7^{\circ} \mathrm{K}$ and $77.4^{\circ} \mathrm{K}$, and the data were found to satisfy the Dubinin-Radushkevich equation. Heats of adsorption were calculated and determined to be within a range of 1.1 to $1.7 \mathrm{kilocalories} / \mathrm{mole}$. Before making measurements on steel, physical adsorption measurements were made for the well-studied case of nitrogen on 7740 Pyrex glass to evaluate the vacuum system and the validity of the technique used. The maximum possible error in the data obtained by using the present technique has been estimated to be 40 percent.

17. Key Words (Suggested by Author(s))

18. Distribution Statement

Physical adsorption

Surface phenomena

Interaction of gases with surfaces

Gas-solid interface

19. Security Classif. (of this report)

Unclassified
20. Security Classif, (of this page)

Unclassified
Unclassified - Unlimited -..

* For sale by the Clearinghouse for Federal Scientific and Technical Information Springfield, Virginia 22151 


\section{CONTENTS}

SUMMARY . . . . . . . . . . . . . . . . . . . . . . . . . . . . . 1

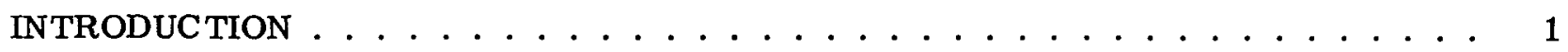

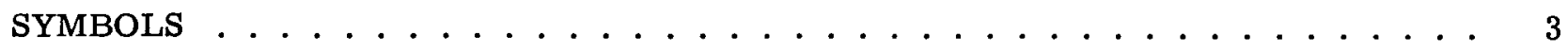

BACKGROUND STUDIES . . . . . . . . . . . . . . . . . . . . . 5

Physical Adsorption on Metals ......................... 5

Surface Characterization . . . . . . . . . . . . . . . . . . . . 6

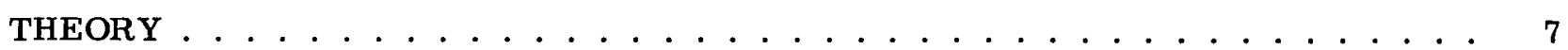

The Dispersion Interaction . . . . . . . . . . . . . . . . . . . . 7

The Repulsive Interaction . . . . . . . . . . . . . . . . . . . . . . . 9

Thermodynamics of the Adsorption . . . . . . . . . . . . . . . . . . 10

APPARATUS . . . . . . . . . . . . . . . . . . . . . . . . . . 11

System Components . . . . . . . . . . . . . . . . . . . . . . . 11

Material Surfaces . . . . . . . . . . . . . . . . . . . . . 16

EXPERIMENTAL PROCEDURE .......................... 18

Surface Characterization . . . . . . . . . . . . . . . . . . . . 18

Adsorption Measurement . . . . . . . . . . . . . . . . . . . . 19

RESULTS AND DISCUSSION . . . . . . . . . . . . . . . . . . . . . . . 23

Surface Characterization . . . . . . . . . . . . . . . . . . . . 23

Adsorption Studies . . . . . . . . . . . . . . . . . . . . . . . 28

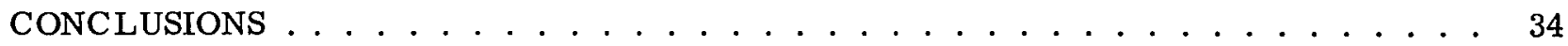

APPENDIX A - UNCERTAINTY IN THE ADSORPTION MEASUREMENT . . . . . . . 35

The Pumping Speed S . . . . . . . . . . . . . . . . . . 36

The Constant B. . . . . . . . . . . . . . . . . . . . . . . 36

The Expression in Brackets Represented by $\mathrm{Y}$. . . . . . . . . . . . . . . 37

APPENDIX B - DERIVATION OF THE CLAUSIUS-CLAPEYRON ANALOG

EQUATION FOR ADSORPTION . . . . . . . . . . . . . . . . . . . . . . 39

APPENDIX C - DERIVATION OF THE EQUATION TO DETERMINE THE

NUMBER OF ADSORBED MOLECULES $\sigma$. . . . . . . . . . . . . . . . . . . . 43

REFERENCES ............................... 46 


\title{
PHYSICAL ADSORPTION OF NITROGEN GAS ON THE \\ POLISHED SURFACE OF 347 STAINLESS STEEL
}

\author{
AT VERY LOW PRESSURES*
}

\author{
By R. A. Outlaw \\ Langley Research Center
}

\section{SUMMARY}

A combined study of surface characterization and physical adsorption was performed for a material commonly used in vacuum instrumentation and hardware, namely, stainless steel. An attempt to characterize a polished 347 stainless-steel surface was made first by using a large surface area to average out variations in grains and grain orientations (i.e., an average surface character) and later by surface topography and surface-composition measurements. The surface topography was made by optical and electron microscopes, and the composition measurements were made with an ion microprobe mass spectrometer.

Following this study, physical adsorption measurements of nitrogen on polished 347 stainless steel in the pressure range from $1 \times 10^{-9}$ to $1 \times 10^{-7}$ torr were made. Isotherms were plotted for test temperatures of $87.7^{\circ} \mathrm{K}$ and $77.4^{\circ} \mathrm{K}$, and the data were found to satisfy the Dubinin-Radushkevich equation. Heats of adsorption were calculated and determined to be within a range of 1.1 to 1.7 kilocalories $/$ mole.

Before making measurements on steel, physical adsorption measurements were made for the well-studied case of nitrogen on 7740 Pyrex glass to evaluate the vacuum system and the validity of the technique used. The maximum possible error in the data obtained by using the present technique has been estimated to be 40 percent.

\section{INTRODUCTION}

In the last decade, the intense interest in space has greatly advanced the state of the art of vacuum technology. The desire to produce a spacelike environment in the laboratory has resulted in vacuum systems which are capable of approaching the low pressure of space. However, the ability to simulate the pressure of space is, as yet, more than the

*The information presented herein was included in a thesis offered in partial fulfillment of the requirements for the degree of Master of Science, Virginia Polytechnic Institute, Blacksburg, Virginia, January 1969. 
ability to measure that pressure and far more than the ability to determine the constituents of the residual gas and their respective partial pressures. Many problems that have blocked the way have been solved but many still remain to be solved. A major problem that limits accurate pressure measurement and gas-constituent analysis is that of gas adsorption and desorption.

Gas adsorption and desorption may be superficially understood by considering a single gas molecule striking a solid surface. Such a molecule will have either an elastic or inelastic collision. If the collision is elastic, the molecule will be reflected from the surface without significant loss of kinetic energy. If the collision is inelastic, the molecule loses some of its total energy (an amount $q$, the heat of adsorption) to the surface and remains on this surface for a period of time called the residence time. While the molecule remains on the surface, it is said to be adsorbed. When it attains enough energy to leave the surface, it is said to be desorbed.

There are two types of adsorption, physical and chemical. Physical adsorption involves the weak van der Waals forces between the gas and surface molecules and is therefore associated with low heats of adsorption ( $q<10 \mathrm{kcal} / \mathrm{mole}$ ). Chemical adsorption involves the stronger forces found in actual chemical bonds and corresponds to higher heats of adsorption ( $q>10 \mathrm{kcal} / \mathrm{mole}$ ).

The significance of the adsorption-desorption problem becomes increasingly apparent as the pressure to be measured decreases. Since the instruments that measure total pressure and partial pressure in the high-vacuum region function by first ionizing the gas, they are gas-composition sensitive (that is, the gage indicates different readings in different gases at the same pressure). Therefore, to make an accurate measurement, the gases involved and their separate instrument calibrations must be known. Adsorption and desorption of various gases from construction materials of the instrument could result in an inaccurate measurement if this absorption and desorption contribution is not known. Also, the kind and amount of gas adsorbed and/or desorbed by each material need to be known in order to determine qualitatively and quantitatively the actual environmental gases.

It is recognized that the polycrystalline nature of stainless-steel components makes it very difficult to characterize the surface and to answer adsorption questions accurately, but it is also recognized that there is a great deal of vacuum instrumentation and hardware made of this material. Total- and partial-pressure measuring instruments are usually encased in a stainless-steel body, especially if they are constructed for flight use. Information as described in the preceding paragraph would be required for stainless steel, in order to make better total- and partial-pressure measurements. There have been several recent reports on the outgassing of bulk stainless steel (such as refs. 1 and 2) and some reports on the chemical adsorption on stainless steel (such as ref. 3) but few 
reports on physical adsorption characteristics. The purpose of this paper is to present information about the physical adsorption of nitrogen on a polished 347 stainless-steel surface for a pressure range from $1 \times 10^{-7}$ to $1 \times 10^{-9}$ torr and about characterization studies conducted on this surface. An electronic method to determine dynamically the number of molecules adsorbed is utilized in this work.

The paper also includes physical adsorption data for nitrogen on 7740 Pyrex glass. This study was conducted to compare results with those of other experimenters (refs. 4 and 5) so that an evaluation of the vacuum system and the dynamic technique utilized (ref. 6) could be made. An error analysis was made on the adsorption measurements and was found to yield an error of approximately 40 percent. (See appendix A.)

\section{SYMBOLS}

a

B

C

D

d

E

e

F

G

H

$\mathbf{h}$

$\mathbf{i}^{+}$

$\mathrm{i}^{-}$ constant, $\mathrm{cm}^{-1}$

constant, torr $\mathrm{r}^{-1}-\mathrm{sec}^{-1}$

constant, erg- $\mathrm{cm}^{6}$

constant

interatomic spacing between the atoms of solid, $\mathrm{cm}$

energy, ergs

charge of electron

conductance, liters/sec

Gibbs free energy, ergs

enthalpy, ergs

Planck's constant

ion current, amperes

electron emission current, amperes 


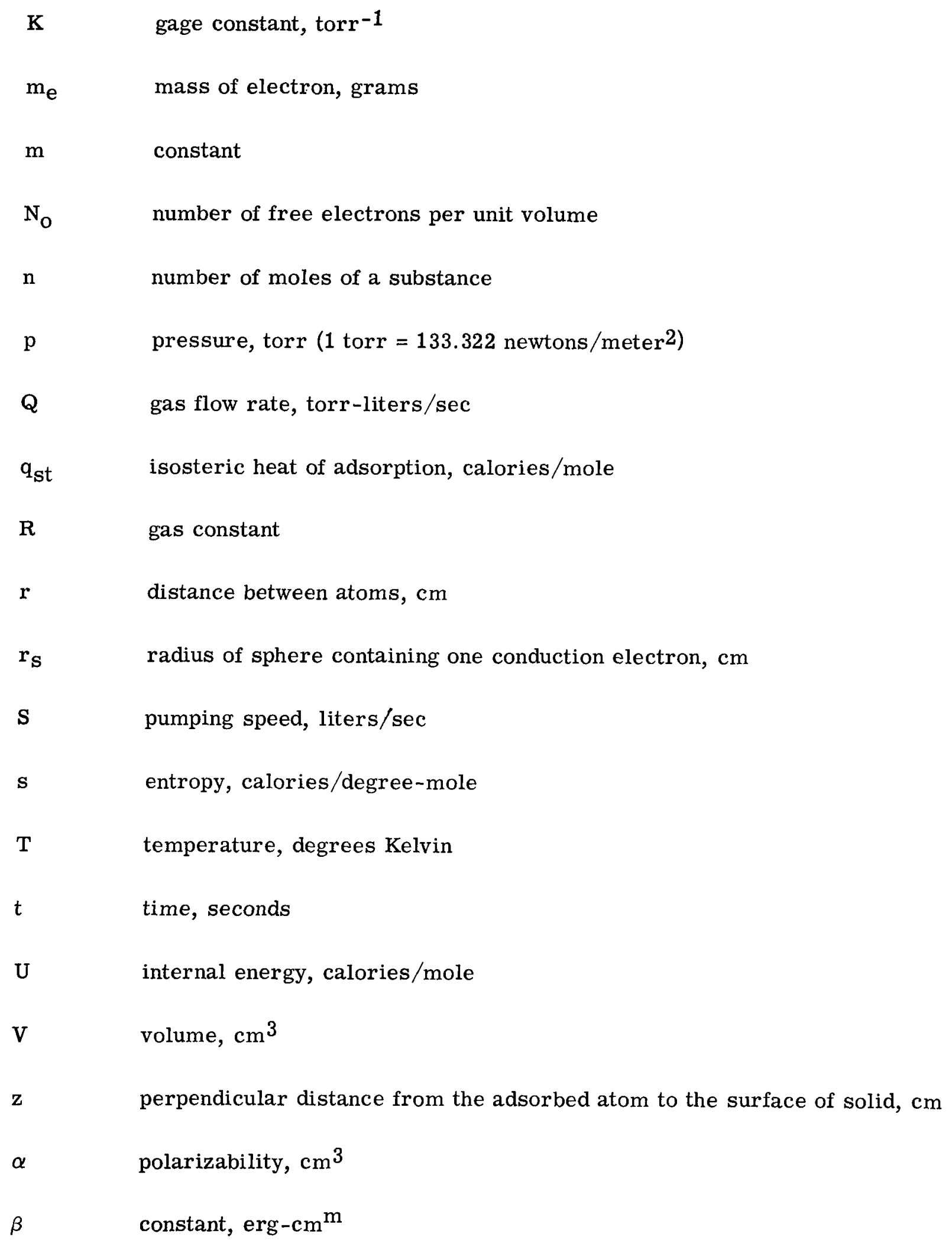




$\begin{array}{ll}\mu & \text { chemical potential, calories } / \mathrm{mole}^{2} \\ \sigma_{\mathrm{m}} & \text { number of molecules of gas adsorbed in a monolayer } \\ \sigma & \text { number of molecules of gas adsorbed per } \mathrm{cm}^{3} \\ \sigma^{*} & \text { number of molecules of gas adsorbed per } \mathrm{cm}^{2} \\ \tau & \text { residence time, sec } \\ \nu_{\mathrm{O}} & \text { characteristic frequency, } \mathrm{sec}^{-1} \\ \theta & \text { relative coverage }\end{array}$

Subscripts:

FC forechamber

MC main chamber

\section{BACKGROUND STUDIES}

\section{Physical Adsorption on Metals}

One of the earliest investigations of physical adsorption on the surface of steel was made in 1943 by Armbruster and Austin (ref. 7). Their work on smooth, cold-rolled steel included the adsorption of $\mathrm{H}_{2}, \mathrm{Ar}, \mathrm{Ne}, \mathrm{N}_{2}, \mathrm{CO}$, and $\mathrm{CO}_{2}$ at temperatures of $293^{\circ} \mathrm{K}, 195^{\circ} \mathrm{K}$, $90^{\circ} \mathrm{K}$, and $78^{\circ} \mathrm{K}$. The lowest equilibrium pressure at which adsorption was studied was $1 \times 10^{-3}$ torr. The pressure range of current interest falls below the lower limit of their investigation; this limit is just at the point below which the information may be of some modern value. Armbruster and Austin found several interesting facts, the most surprising being a surface roughness factor of 1.5 and less for reduced and unreduced samples. (Surface roughness factor is defined as the ratio of the actual adsorption surface area to the geometric surface area.) This value indicates a remarkably flat surface, in view of the fact that on a molecular perspective the scratch marks from polishing are very large. Their determination of the heat of absorption indicated an approximate value of $3 \mathrm{kcal} / \mathrm{mole}$ for both argon and nitrogen. They found the same heat of adsorption to be true for iron, silver, and platinum, and from this they concluded that at a given temperature the heat of adsorption is chiefly a function of the physical state of the surface and is relatively independent of the chemical nature of either adsorbent or adsorbate. 
Armbruster also studied the adsorption of water vapor on a stainless steel alloy at $20^{\circ} \mathrm{C}$ $\left(293^{\circ} \mathrm{K}\right)$ and found that it adsorbed three to four times as much as cold-rolled steel (ref. 8).

Wightman and Mugler, in 1966, investigated the adsorption of $\mathrm{N}_{2}, \mathrm{He}$, and $\mathrm{Ar}$ at room temperature on stainless steel at $10^{-8}$ to $10^{-7}$ torr (ref. 9). The technique utilized in their study was to expand a known volume of gas into another known volume and attribute the pressure difference between the measured and predicted values to adsorption. They found that very little adsorption occurs at room temperature.

There have been investigations into the desorption of gases from steel by elevating its temperature in a vacuum environment and determining the gases desorbed by noting changes in the background mass spectrum with a residual gas analyzer. This includes surface-trapped gases as well as gases diffusing from the bulk to the surface and their subsequent desorption. Degras, Schram, Lux, and Petermann (ref. 3) conducted flashfilament tests on $304 \mathrm{~L}$ stainless steel with an omegatron residual gas analyzer. Their polished stainless-steel filaments were flashed in various ways up to temperatures of $1073^{\circ} \mathrm{K}$.

Ehrlich (ref. 10) has measured, by using the technique of field emission microscopy, the binding energies in physical adsorption of some inert gases on tungsten, molybdenum, and tantalum.

\section{Surface Characterization}

The attempt to characterize a surface for investigation at very low pressures is a formidable task. Even a known crystal face, grown in a most careful manner, thoroughly degreased, and baked out inside a vacuum chamber, may still have contaminants or impurities that affect the gas interaction with the surface. Farnsworth (ref. 11) has reported that contaminants as small as 1 to 5 percent have an observable effect on surface studies. Techniques such as field ion emission, low-energy electron diffraction, mass spectrometry, and work-function measurements have been successfully used to detect surface contaminants but it is a rare situation when all contaminants have been completely determined and measured. Also, complete repeatability of a surface experiment requires that even the histories of two like samples be identical in order to insure that the same contaminants (kind and amount) and impurities are in both. If, without destroying its homogeneity, a surface could be cleaned of its oxide layer, contaminant, or impurity, and the surface thus be made representative of the bulk, a repeatable surface would be obtained. Further surface experiments require the monolayer formation time to be long compared with the test time, a condition which usually requires pressures to be in the ultrahigh-vacuum region. Bradford (ref. 12) found that ion bombardment (argon) used in conjunction with heating of the surface provided an effective way of cleaning. 
After several cycles of ion bombardment and heating of a polycrystalline nickel surface, he found that the work function became a constant value. The problem experienced with this technique was that the ion bombardment destroyed the surface homogeneity by its sputtering action. Electron bombardment and chemical reduction of a surface (by bleeding hydrogen into the vacuum chamber) are popular techniques used to remove an oxide layer. The problem is that such processes do not always work on strongly bonded oxides. One of the best techniques reported in the literature for obtaining a clean surface is to cleave a substance in an ultrahigh-vacuum environment. Bryant (ref. 13) has made studies on lamellar solids and experimentally determined the binding energies. This requires a substance, however, which has weak bonding between atomic planes, such as graphite.

\section{THEORY}

Physical adsorption can be discussed by considering the interaction between a visitor atom or molecule and the surface with which it comes in contact. If it is a neutral, nonpolar species, it will experience an attractive dispersional force (van der Waals force) arising from the interaction between the instantaneous dipoles of the visitor atom and the surface atoms. This is a relatively long-range force. Remember that if the visitor atom comes very close to the surface, the interaction energy contains effects due to wave function overlap which give rise to exchange integrals that result in a repulsive force. It is the combination of these two interactions which yields a net attractive force binding the visitor atom to the surface.

\section{The Dispersion Interaction}

The interaction between a visitor atom and the surface atoms due to the attractive van der Waals force may be thought of as the force which comes from the constant a in the van der Waals gas law (ref. 14). If the adsorbed atom has no permanent dipole moment (or any multipole moment) and if the solid has no external electric field, the attractive interaction with the solid surface is entirely due to nonpolar dispersion forces. If the adsorbed atom does have a permanent dipole (or multipole moment), additional interactions with the solid surface occur. These additional interactions give rise to Debye induction and Keesom orientation effects (ref. 15). The quadrupole moment of the nitrogen molecule produces a very small effect relative to the dispersion interaction and is not to be considered herein.

The dispersion energy $\mathbf{E}$ between two individual neutral atoms has been derived by London (ref. 16) to be 


$$
E=-\frac{C}{r^{6}}
$$

where $\mathbf{C}$ is a constant for the given atoms and $\mathbf{r}$ is the distance between atoms.

The constant $\mathrm{C}$ has also been determined by London and others with varying success. The equation for $C_{L}$, the value of $C$ derived by London, by using the perturbation theory is

$$
\mathrm{C}_{\mathrm{L}}=\frac{3}{2} \alpha_{1} \alpha_{2}\left(\frac{\mathrm{I}_{1} \mathrm{I}_{2}}{\mathrm{I}_{1}+\mathrm{I}_{2}}\right)
$$

where $I_{1}$ and $I_{2}$ are characteristic energies (often ionization potentials) and $\alpha_{1}, \alpha_{2}$ are polarizabilities of atoms 1 and 2 , respectively.

Extending this interaction between one atom and an entire solid surface gives the expression for the total interaction

$$
E=\sum_{\mathbf{i}} \mathrm{E}_{\mathbf{i}}
$$

where $E_{i}$ is the interaction energy between the atom and the ith atom of the solid.

Considering the potential theory of Polanyi (ref. 15), London replaced the summation by an integral and obtained the following result for $\sigma$ molecules adsorbed on the surface:

$$
E=-\frac{\sigma \pi C_{L}}{6 z^{3}} \quad(z \gg d)
$$

where $\mathrm{z}$ is the perpendicular distance from the adsorbed atom to the surface of the solid, and $d$ is the interatomic spacing between the atoms of the solid.

Margenau and Pollard (ref. 17) developed the following equation, subsequent to criticism by Lennard-Jones (ref. 18) of London's work when applied to metals,

$$
E=-\frac{\mathrm{e}^{2} \alpha}{8 \mathrm{z}^{3}}\left[-\frac{\mathrm{hN}}{2 \pi \mathrm{m}_{\mathrm{e}} \nu_{\mathrm{o}}}+\frac{5}{4 \mathrm{r}_{\mathrm{s}}}\right] \quad(\mathrm{z} \gg \mathrm{d})
$$


where

h Planck's constant

$\mathrm{N}_{\mathrm{o}} \quad$ number of free electrons per unit volume

$\mathrm{m}_{\mathrm{e}} \quad$ mass of electron

$r_{\mathrm{S}} \quad$ radius of sphere containing one conduction electron

Margenau and Pollard obtained results for $\mathrm{H}_{2}, \mathrm{He}, \mathrm{Ar}, \mathrm{Ne}$, and $\mathrm{N}_{2}$ gases on several monovalent and bivalent metals. However, it is apparent from a review of the literature that there is no theory which accurately predicts a result comparable with experiment for an entire set of systems.

\section{The Repulsive Interaction}

The short-range exchange forces arising from the overlap of electronic clouds of the adatom and the conduction-band electrons of the metal are repulsive in character. They become important for very short interatomic distances. (ref. 19)

The repulsive interaction energy $E_{\mathbf{r}}$ between two atoms may be represented by

$$
\mathbf{E}_{\mathbf{r}}=\beta \exp (-\mathrm{ar})
$$

where $\beta$ and a are positive constants. Typical values of these constants determined by Kunimune (p. 18 of ref. 19) for argon are $\beta=55.5 \times 10^{-7}$ erg and $a=3.68 \AA^{-1}$. A second empirically based formula extensively used for determining the repulsive interaction (ref. 19) is

$$
\mathbf{E}_{\mathbf{r}}=\beta \mathbf{r}^{-\mathrm{m}}
$$

where $\beta$ and $m$ are constants for the system.

If the repulsive interaction between an adsorbed atom and the entire solid surface is considered and equation (7) is integrated over $\mathrm{N}$ atoms per unit volume of the solid, the following result is obtained (ref. 19):

$$
E(z)=\frac{2 \pi N \beta}{(m-3)(m-2)} z^{3-m}
$$


Finally, the binding energy that holds a physically adsorbed atom to the surface must be the combination of all the interactions which play a role in the process. Therefore, the net binding energy of the adatom is given by the following equation:

$$
\mathrm{E}_{\text {binding }}=\mathrm{E}_{\text {attractive }}+\mathrm{E}_{\text {repulsive }}
$$

It is this net binding energy that is measured by finding the isosteric heat adsorption $\mathrm{q}_{\mathrm{st}}$.

\section{Thermodynamics of the Adsorption}

In general, the physical adsorption of a gas on a solid is an exothermic process, regardless of the nature of the forces involved. Thus, for physical adsorption

$$
\Delta H=\Delta G+T \Delta S
$$

where

$\begin{array}{ll}\text { H } & \text { enthalpy } \\ \text { G } & \text { Gibbs free energy } \\ \text { T } & \text { temperature } \\ \text { S } & \text { entropy }\end{array}$

Since the adsorption results in a decrease in free energy and entropy, the enthalpy must decrease.

What is desired here is to determine the binding energy of the adsorbate to the adsorbent by experimentally obtaining the heats of adsorption. The adsorption isotherm is given by

$$
\sigma_{\mathrm{S}}=[\mathrm{f}(\mathrm{p})]_{\mathrm{T}}
$$

where

T absolute temperature

$\sigma_{\mathrm{S}} \quad$ number of moles of adsorbed gas

$\mathrm{p}$

equilibrium pressure above adsorbed layer

By varying the equilibrium pressure with respect to the temperature for a given $\sigma_{\mathbf{S}}$, the heat of adsorption can be determined by constructing adsorption isosteres from 


$$
p=[f(T)]_{\sigma_{S}}
$$

and measuring their slopes. The isosteres can be analytically related to the ClausiusClapeyron equation in the form

$$
\left[\frac{\partial \ln p}{\partial \frac{1}{T}}\right]_{\sigma_{S}}=-\frac{q_{S t}}{R}
$$

where the quantity in the brackets is taken at constant coverage ${ }^{1}$ and $\mathrm{q}_{\mathrm{st}}$ is the isosteric heat of adsorption. (For the derivation of this equation see appendix B.)

\section{APPARATUS}

\section{System Components}

The system block diagram is shown in figure 1. The experimental apparatus with electronics is shown in figures 2 and 3 . The system is composed of a main chamber, a forechamber, two ion pumps, a sorption pump, a 2-inch $(5.08-\mathrm{cm})$ diffusion pump system, molecular leak, two calibrated ion gages, a thermocouple gage, a residual gas analyzer, copper-constantan and chromel-alumel thermocouples, a storage volume, numerous valves, flanges, and vacuum hardware.

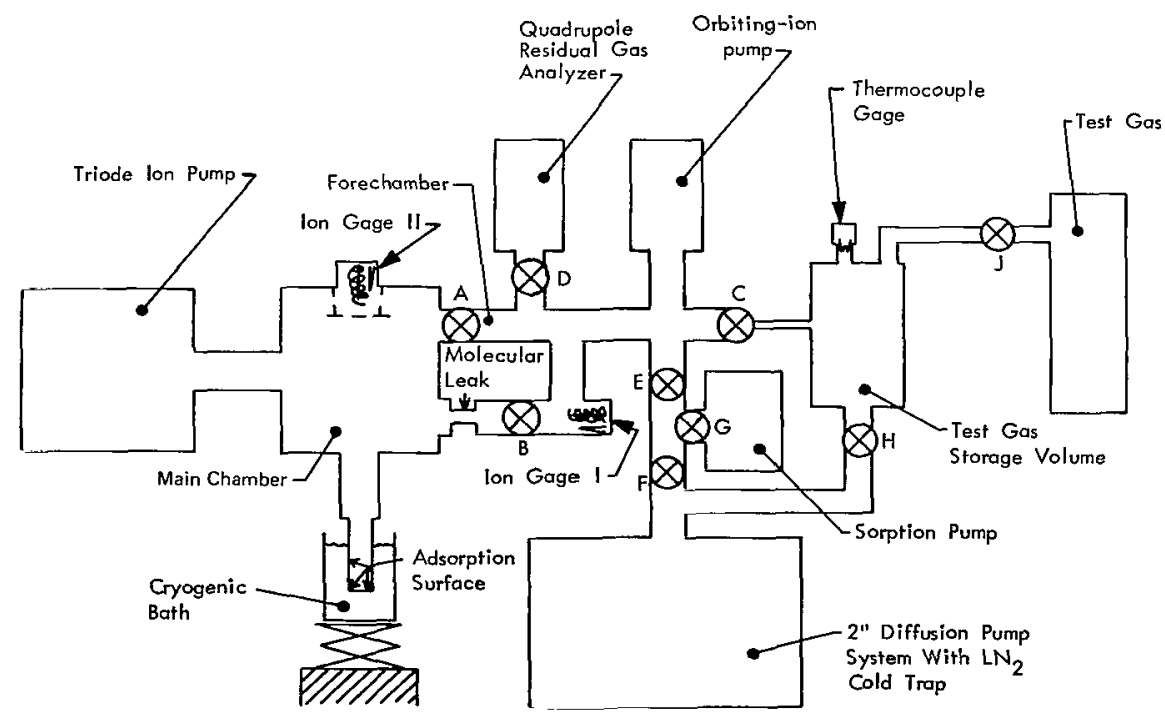

Figure 1.- System block diagram.

${ }^{1}$ Constant coverage is used here to infer an equal number of molecules $/ \mathrm{cm}^{2}$. 


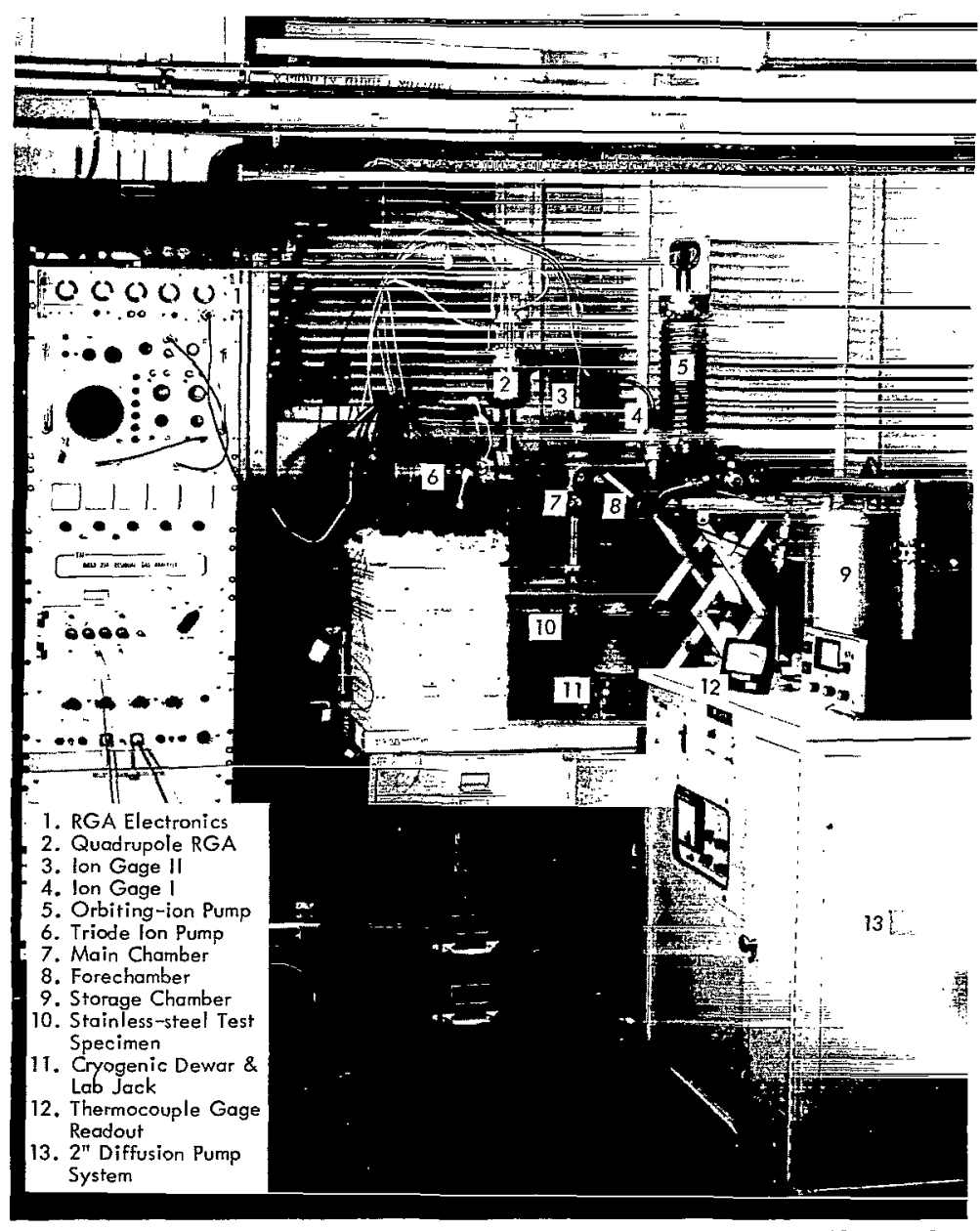

Figure 2.- Front view of system.

I-68-10989

Main chamber (MC). - The main chamber encases the surface to be studied and ion gage II. The main chamber is constructed of 347 stainless steel and has an operating volume of approximately $2000 \mathrm{~cm}^{3}$. The inside surface was chemically etched to lower its outgassing rate. During bakeout, valves A and B are open. During the experiment, valve $A$ is closed.

Forechamber (FC).- The forechamber encases ion gage I and is separated from the main chamber by a short-tube molecular leak and valves $A$ and $B$. It is constructed of 347 stainless steel and has a volume of approximately $1000 \mathrm{~cm}^{3}$ (volume enclosed by valves $A, B, C, D$, and $E$ ). It is evacuated during operation by the orbiting-ion pump, with valves $A$ and $E$ closed. During bakeout, all valves except $C$ are open.

Ion pumps. - Two ion pumps are employed in this system. The first is a triode ion pump which has a pumping speed at the pump throat of 100 liters/sec for dry air. This pump is used for pumping of the main chamber. 


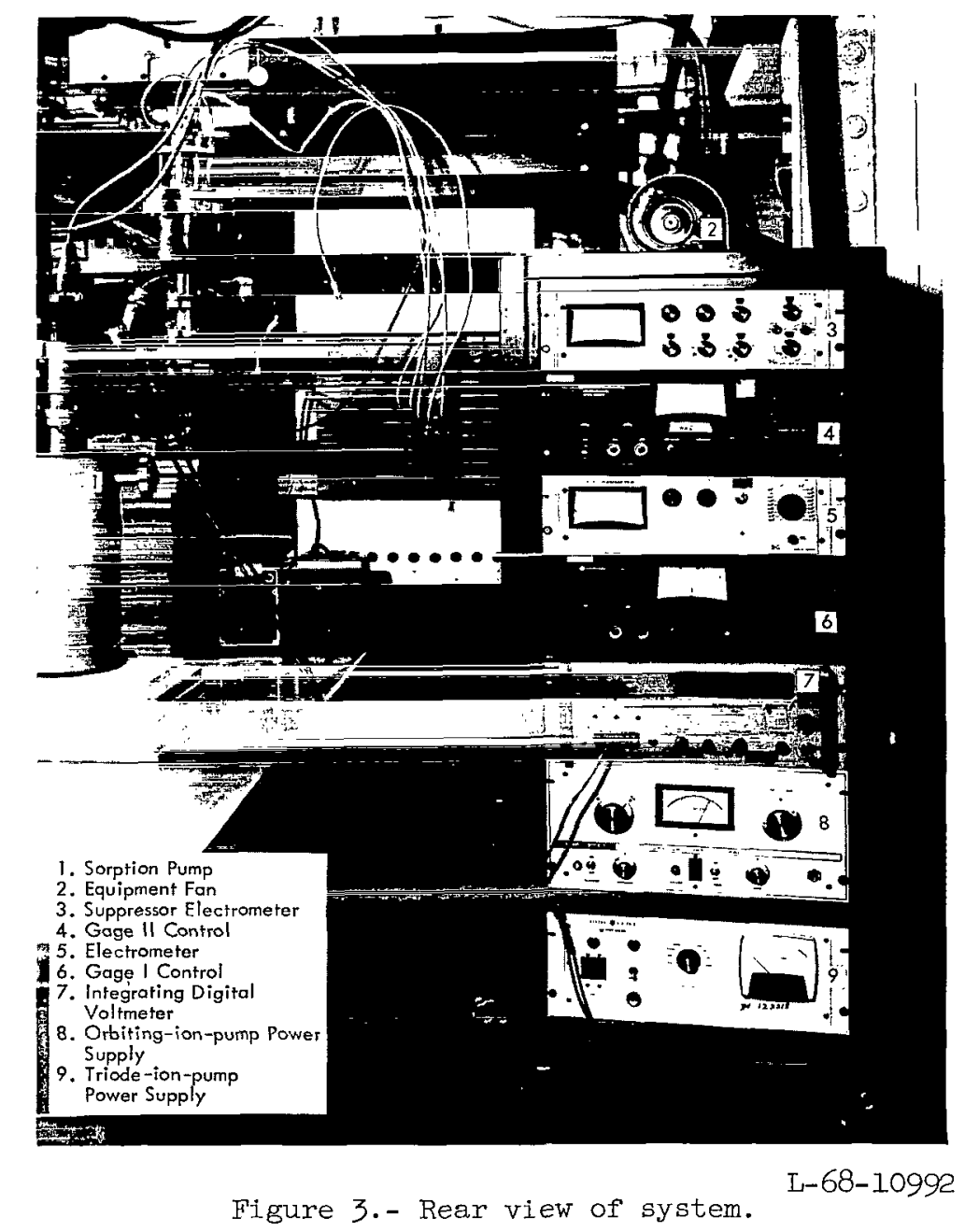

The pumping speed for nitrogen at the entrance into the main chamber has been calculated to be approximately 50 liters/sec (at 10-10 torr) but varies with pressure.

The second ion pump employed is an orbiting-ion getter pump. It has a pumping speed at the pump throat of approximately 400 liters/sec for dry air. This pump is used for evacuation of the forechamber. During experimentation, it is valved off at valve $A$ from the main chamber. The pumping speed for dry nitrogen at the main chamber entrance (observed during bakeout), considering the conductance, is approximately 5 liters/sec. The pumping speed for nitrogen in the forechamber at ion gage $I$ is also about 5 liters/sec.

Sorption pump.- The sorption pump is essentially a molecular sieve material and it was used only to "rough" the entire system from atmospheric pressure to about $2 \times 10^{-3}$ torr. No determination of its pumping speed was made. 
2-inch diffusion pump system.- A 2 -inch $(5.08 \mathrm{~cm})$ oil diffusion pump backed by a mechanical roughing pump is used for initial evacuation of the system and for pumping during bakeout.

Short-tube molecular leak. - This short-tube molecular leak separates the main chamber from the forechamber and provides a way of inbleeding small amounts of the test gas into the main chamber from the forechamber. It is constructed of 347 stainlesssteel tubing and is $3.3 \mathrm{~cm}$ long and $0.325 \mathrm{~cm}$ in diameter. Determination of the conductance $\mathbf{F}$ of the leak can be made from the short-tube formula derived by Clausing (ref. 20) with the use of a corrected transmission probability determined by Helmer (ref. 21.) The gas flow rate $Q$ through the leak into the main chamber is

$$
\mathrm{Q}_{\mathrm{N}_{2}}=\mathrm{F}\left(\mathrm{p}_{\mathrm{FC}}-\mathrm{p}_{\mathrm{MC}}\right)
$$

where $\mathrm{p}_{\mathrm{FC}}$ is the pressure in the forechamber and $\mathrm{p}_{\mathrm{MC}}$ is the pressure in the main chamber. Since $p_{F C} \gg p_{M C}$ when the test gas is admitted into the forechamber, the flow rate is

$$
\mathrm{Q}=\mathrm{Fp}_{\mathrm{FC}}
$$

Ion gages. - Two ionization gages of the closed-end Bayard-Alpert type (ref. 22), herein called B-A gage, were used to measure the pressure. (See fig. 4.) Both are nude gages and are mounted inside the system. In the main chamber (gage II), the gage was modified to take a modulator element. This modification enables pressures as low as $4 \times 10^{-12}$ torr to be measured (ref. 23). The gage is operated at an emission current of 4 milliamperes. In the forechamber a B-A gage (gage I) without the modulator was used. It operated at an emission current of 40 microamperes. The controls for these gages provide 180 volts dc to the grid and 45 volts dc to the filament, and the collector is tied through an electrometer to the ground. The modulated gage has an extra collector (modulator) which is either at grid potential or ground. The electrometer 
used for ion current measurements for gage II has suppressor current capability. The ion current is related to the pressure by the expression

$$
\frac{\mathrm{i}^{+}}{\mathrm{i}^{-}}=\mathrm{Kp}
$$

where

$\begin{array}{ll}\mathrm{K} & \text { gage constant } \\ \mathrm{i}^{+} & \text {ion current } \\ \mathrm{i}^{-} & \text {emission current } \\ \mathrm{p} & \text { pressure }\end{array}$

In order to determine $\mathrm{K}$, both gages were calibrated on an orifice system based on a calibration system described by Hayward and Jepsen (ref. 24).

Thermocouple gage. - The thermocouple gage is a compensating gage which indicates the pressure from atmosphere down to the limit of the mechanical pump. It measures the pressure in the storage volume. Its power control delivers 0.38 volt ac to heat the thermocouples. At a vacuum of $1 \times 10^{-4}$ torr, the gage output voltage is 10 millivolts dc.

Residual gas analyzer (RGA). - The instrument used for determining the residual gases in the main chamber is a mass spectrometer. Basically, it is a quadrupole mass separator with an electron multiplier, fitted to a 2.75 -inch $(6.99 \mathrm{~cm})$ metal flange. It utilizes an ordinary hot-filament ion source and separates the different ion species by superimposed rf and dc voltage fields applied on four symmetrically arranged metal rods. This instrument was used only to determine, qualitatively, the kinds of gases and their changes in the background environment.

Special electronics. - An integrating digital voltmeter was used for calculating the area under the pressure-time curve. This instrument is capable of continuous integration and, when used in conjunction with the suppressor electrometer, allows a way of electronically measuring the number of molecules being adsorbed on a surface.

Valves. - All valves used in the system are 1.5 -inch $(3.8 \mathrm{~cm})$ bakeable valves with metal seals except for the needle valves used on the gas source and the bleed valve.

Storage volume. - The storage volume is a 4-liter chamber made of aluminum. It is used for providing an ample supply of test gas before the bleed valve $C$ in order to cut down pressure fluctuations in the forechamber. 
Test gas.- The test gas used in this experiment was prepurified nitrogen with an impurity count of less than $20 \mathrm{ppm}$. Since it was expected that nitrogen gas would not react chemically with the metallic surfaces in the main chamber at room temperature or lower, it was believed that it was suitable for physical adsorption studies. Nitrogen was also selected as a test gas because of its frequency appearance as an outgassing product.

Cryogenic liquids. - Cryogenic liquids were used to attain the isotherm temperatures. Liquid nitrogen was used to cool the steel to a temperature of $77.4^{\circ} \mathrm{K}$, and liquid argon was used to cool the steel to a temperature of $87.7^{\circ} \mathrm{K}$.

\section{Material Surfaces}

The 347 stainless-steel surface was chosen because it is the one most prevalent among vacuum hardware materials utilized at the Langley Research Center. Pyrex glass was also chosen to be studied although adsorption data on 7740 Pyrex has already been collected by Hobson, Ricca, Bellardo, and Medana (refs. 25 and 26). Repeating Hobson's work, however, provided confidence in the dynamic technique used and pointed out problems that might have been overlooked in the subsequent study of the stainless steel.

Surface preparation.- The steel surface was polished smooth in the same manner as it was by Armbruster and Austin (ref. 7) in their tests on cold-rolled steel. It was prepared by lathe machining to an unevenness of less than 16 microinches ( 0.41 micron) and by successive grindings with silicon carbide paper (400 to 600 ). It was rough polished with metallurgical paper ( 1 to 3 ) and then given a final polish by using a paste of levigated alumina and water applied with lens grinding pads. An average profilometer reading of less than 3 microinches ( 0.08 micron) was determined. The 347 stainlesssteel samples used for the characterization study were prepared in an identical manner. The pyrex surface was not altered from its original state.

All surfaces were then prepared for the vacuum chamber by cleaning successively with acetone, Freon 12, and methanol. Before adsorption tests were made, each surface was outgassed (heating with individual heater tapes wrapped around the outside of the cylinder) to a temperature of $400^{\circ} \mathrm{C}\left(673^{\circ} \mathrm{K}\right)$ for a period of time in excess of 48 hours and at a pressure below $1 \times 10^{-7}$ torr.

Surface geometry. - The pyrex surface was constructed in the shape of a test tube and fused to a kovar glass-to-metal seal. The kovar end was welded to a stainless-steel flange. (See fig. 5.) The dimensions of the pyrex assembly are 

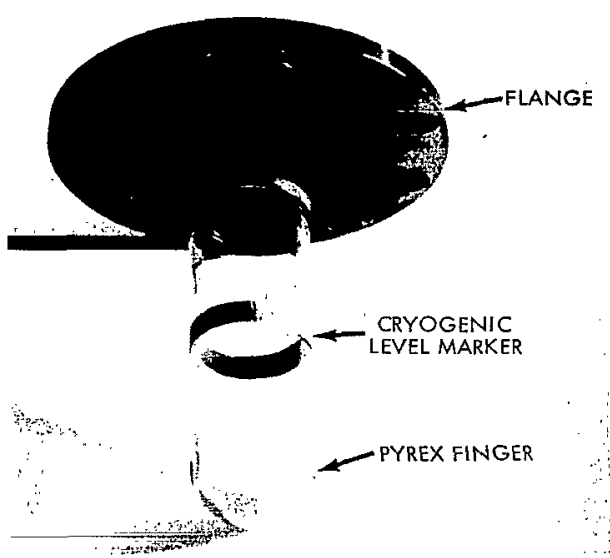

I-68-10991

Figure 5.- Pyrex finger used for adsorption study. Inside area below cryogenic level marker is $49.9 \mathrm{~cm}^{2}$.

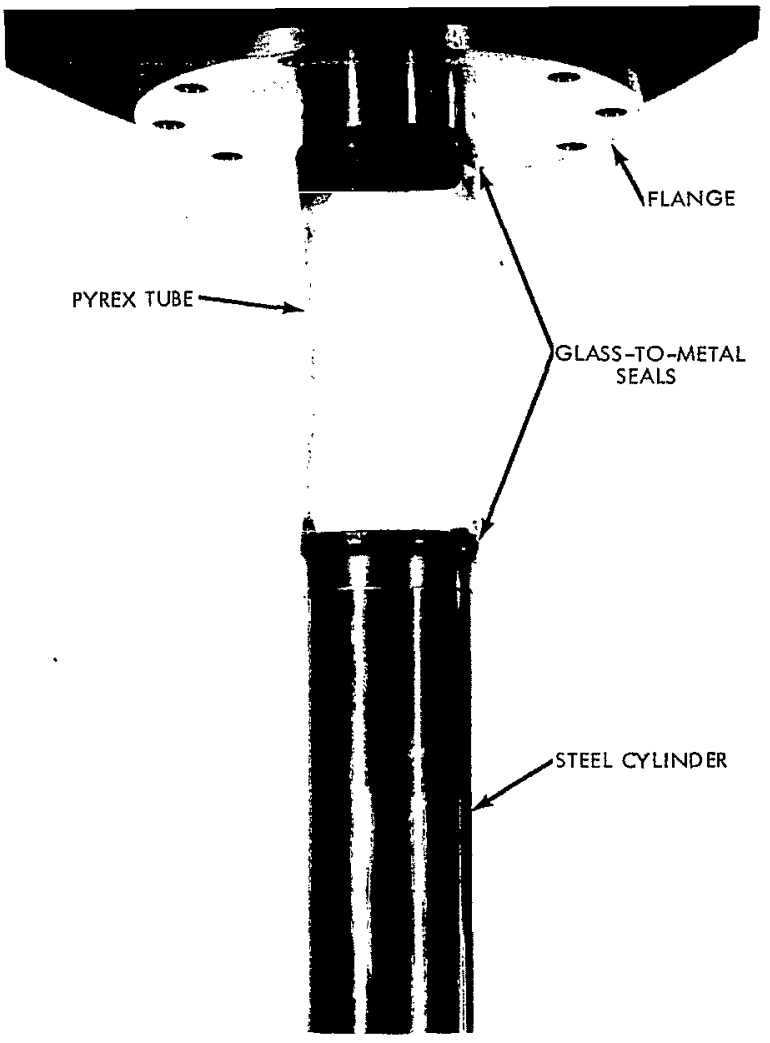

Figure 6.- External view of 347 stainlesssteel adsorption cylinder and flange.
Inside diameter . . . $2.9 \mathrm{~cm}$

Outside diameter . . $3.1 \mathrm{~cm}$

Overall length . . . . $11.9 \mathrm{~cm}$

The 347 stainless-steel adsorption cylinder was electron-beam welded to the kovar end of a glass-to-metal seal which was fused to the glass end of a second kovar glass-tometal seal. This kovar end was welded to a stainless-steel flange. (See fig. 6.) The dimensions of the cylinder assembly are

Inside diameter . . . $3.7 \mathrm{~cm}$

Outside diameter . . . $3.8 \mathrm{~cm}$

Overall length . . . . $17.0 \mathrm{~cm}$

The 347 stainless-steel samples used for the characterization study are shown in figure 7. The dimensions of these samples are
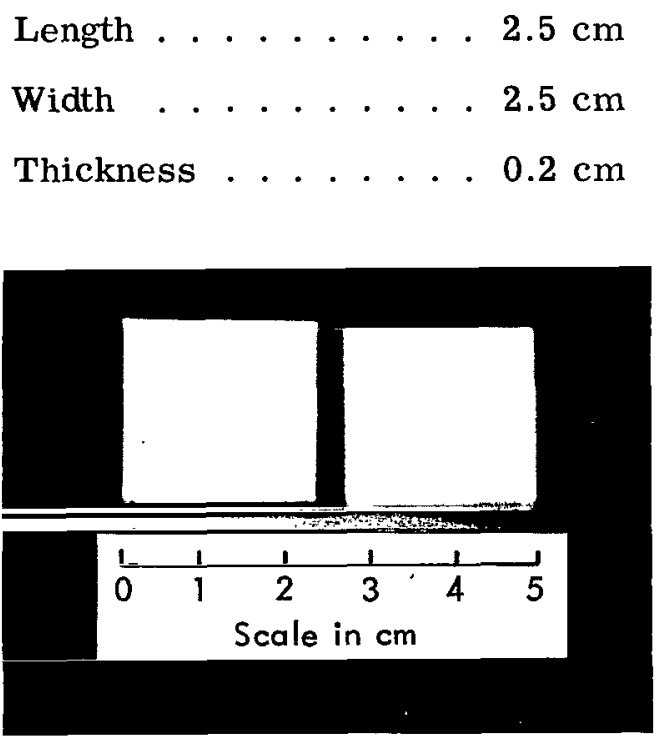

Figure 7.- 347 stainless-steel samples used for characterization study. 


\section{EXPERIMENTAL PROCEDURE}

\section{Surface Characterization}

Most of the surface-characterization techniques mentioned previously do not provide a practical surface, that is, one that occurs in vacuum instrumentation. The need exists for practical adsorption data that might be useful in determining an accurate partial-pressure on total-pressure measurement by using available vacuum instrumentation. The stainless steel used in these instruments is usually cleaned in vacuum by heating to temperatures from $400^{\circ}$ to $450^{\circ} \mathrm{C}\left(673^{\circ}\right.$ to $\left.723^{\circ} \mathrm{K}\right)$. Bakeouts at higher temperatures usually give sealing problems. Outgassing studies by Degras, Schram, Lux, and Petermann (ref. 3) have shown that the gas load evolving from stainless steel after a $400^{\circ} \mathrm{C}$ bakeout for 48 hours is slightly less than $1 \times 10^{-12}$ torr-liters $/ \mathrm{sec} / \mathrm{cm}^{2}$. This result indicates some degree of repeatability as far as cleanliness is concerned. In regard to the polycrystalline nature of stainless steel, it was believed that a characteristic surface could be obtained by using a large surface area $\left(\sim 100 \mathrm{~cm}^{2}\right)$ so that the various differences due to the polycrystalline nature and individual grain orientation are averaged out. In other words, if two 347 stainless-steel surfaces are "cleaned" as described, and if the many grains and grain orientations are, in sum, of a similar average character, the adsorption would be the same.

The 347 stainless-steel surface characterization required information about its topography and its composition. The test samples were studied under four different microscopes in order to establish surface topography.

1. Optical microscope (Langley Research Center)

2. Scanning electron microscope (Langley Research Center)

3. Scanning electron microscope (Goddard Space Flight Center)

4. Transmission electron microscope (Langley Research Center)

The surface composition was difficult to determine. It was suspected that since the stainless steel was heated, chromium from the bulk would diffuse toward the surface. It was also suspected that the thickness of the oxide layer would increase with the heating. Two samples (one unbaked) were analyzed in an ion microprobe solids mass spectrometer. This analyzer functions by bombarding the surface with a beam of high-energy inert gas ions (generated by a plasmatron). (See ref. 25.) Part of the sputtered material from the sample is ionized and these ions are analyzed by a double-focusing analyzer section. The spectrum is obtained by varying the magnetic field instead of varying the accelerating potential. Three mass spectra of the baked sample and three mass spectra of the unbaked sample were taken. An oxygen profile measurement was also made on each sample. Argon ions were used as the bombarding medium at a potential of 10 kilovolts and a current of 0.25 microampere. 


\section{Adsorption Measurement}

There are several ways to determine the data needed to construct adsorption isotherms. The two most often used approaches are called static and dynamic. The static technique is popular and has been used for a number of years by many researchers as noted in reference 25. This technique involves bleeding a test gas into a vacuum chamber where the test surface is located and then isolating the chamber by closing the valve. The pressure in the chamber is noted and the test surface is then cooled to a predetermined isotherm temperature. The pressure in the chamber is again noted and this difference in gas phase pressure is related through the perfect gas law to the molecules adsorbed onto the test surface. In this technique, corrections must be made for the pumping of the gage and for the valve closure effect, that is, the addition to the gas phase of adsorbed molecules on the valve, released by valve closure. The ion pumping of the gage is minimized by operating at low emission currents, but the effect is still significant, especially at low pressures.

More recently, the dynamic technique has become popular (refs. 5 and 6). As the term dynamic implies, there is gas flow. A constant number of molecules in the test chamber is established by bleeding in at a constant flow rate and pumping out at a constant rate. When the test surface in the chamber is cooled to isotherm temperature, the equilibrium is upset until the surface stops adsorbing and the equilibrium returns. By integrating this time change of the pressure, the number of molecules adsorbed can be determined through the molecular balance equation.

The advantages of the dynamic method over the static method are essentially threefold. First, significantly lower equilibrium pressures are obtainable because the test chamber is always being pumped and the pressure contribution from the outgassing of the walls is kept much lower. Second, there are no problems from gage pumping effects since they are accounted for in the molecular balance equation. A third advantage is that no valves (except the bleed valve) must be opened or closed during the experiment. The biggest disadvantage of this technique is that flow rates and pumping speeds must not fluctuate if precise measurements are to be made.

The usual method for integrating the pressure-time variation in the dynamic technique is to plot the curve and then integrate the area with a planimeter. In the present investigation, the dynamic technique has been used along with the electronic method of integrating the pressure-time integral. Details of the experimental procedure are outlined as follows.

The vacuum system was initially given a thorough bakeout to a temperature of $400^{\circ} \mathrm{C}\left(673^{\circ} \mathrm{K}\right)$. The gages were then given a thorough degassing. The bottled prepurified test gas, prior to admittance into the forechamber, was admitted into a 4-liter 
storage volume that had been previously evacuated to 33 microns pressure. After several purgings, storage volume pressure was then adjusted to a pressure of 1 atmosphere of nitrogen. After several minutes, to allow enough time for the pressure in the storage volume to reach equilibrium, valve $C$ was opened and the test gas was bled into the forechamber. The pressure in the forechamber was increased until the pressure in the main chamber was at the lowest equilibrium pressure $\left(p_{M C}=p_{0}\right)$ desired for the isotherm. ${ }^{2}$ Since the hydrogen and other residual gases made up a background pressure of $2 \times 10^{-11}$ torr, the pressure in the main chamber was elevated 2 decades to insure less than a 1-percent contribution from the background gases. Figure 8 shows a residual gas analysis in the main chamber at approximately $5 \times 10^{-9} \operatorname{torr}\left(\mathrm{N}_{2}\right)$. A period of $5 \mathrm{~min}-$ utes was allowed to insure a steady, constant, equilibrium pressure $p_{0}$.

The equation for determining the number of molecules adsorbed, derived in appendix $\mathrm{C}$, is

$$
\sigma(t)=\frac{Q}{B}\left(t-t_{o}\right)-\frac{S}{B} \int_{t_{0}}^{t} p(t) d t
$$

where $t_{o}$ is starting time. At equilibrium in the main chamber

$$
\mathrm{Q}=\mathrm{Sp}_{\mathrm{O}}
$$

and equation (17) becomes

$$
\sigma(t)=\frac{S}{B}\left[p_{o}\left(t-t_{o}\right)-\int_{t_{o}}^{t} p(t) d t\right]
$$

Thus, any change in the experimentally measured pressure-time plot represents the difference between the two terms on the right-hand side in equation (19). This change is represented graphically in figure 9.

At this point, the suppressor on the electrometer was adjusted to the same current as indicated by the electrometer. This nulled the equilibrium pressure $p_{o}$ so that any change in the system equilibrium was recorded from a zero reference. The integrating digital voltmeter (hereafter referred to as IDVM) was set for 0 volt-seconds and turned to Start. The adsorption cylinder was then cooled by the cryogenic liquid. Several minutes elapsed before the surface reached isotherm temperature, depending on the

2 The ultimate pressure attained after the system bakeout was composed primarily of hydrogen. This can be understood since hydrogen is soluble in steel and permeates through the metal from the atmosphere. 


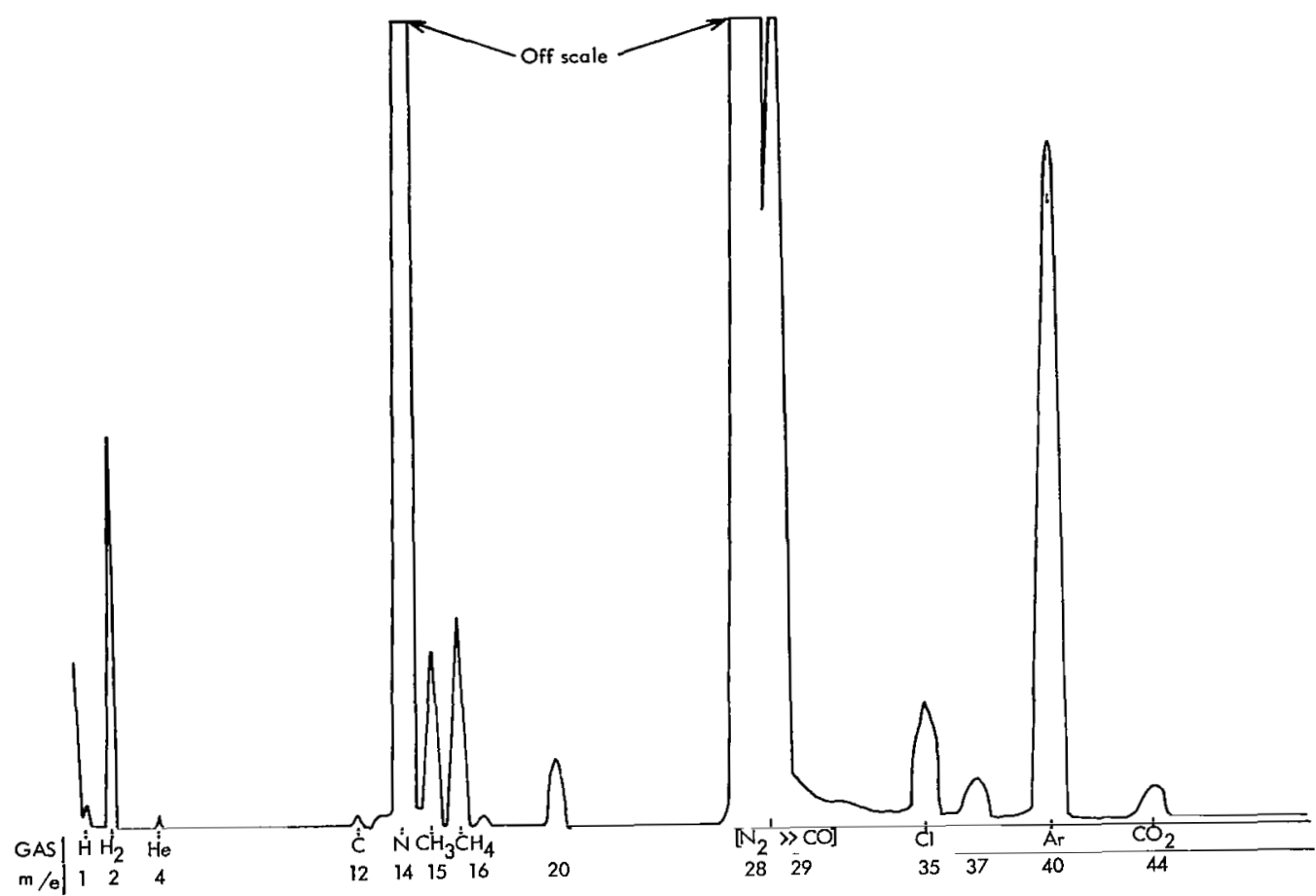

Figure 8.- Residual gas analysis of background gases in main chamber observed during actual run. High argon peak due to contaminated gas regulator valve.

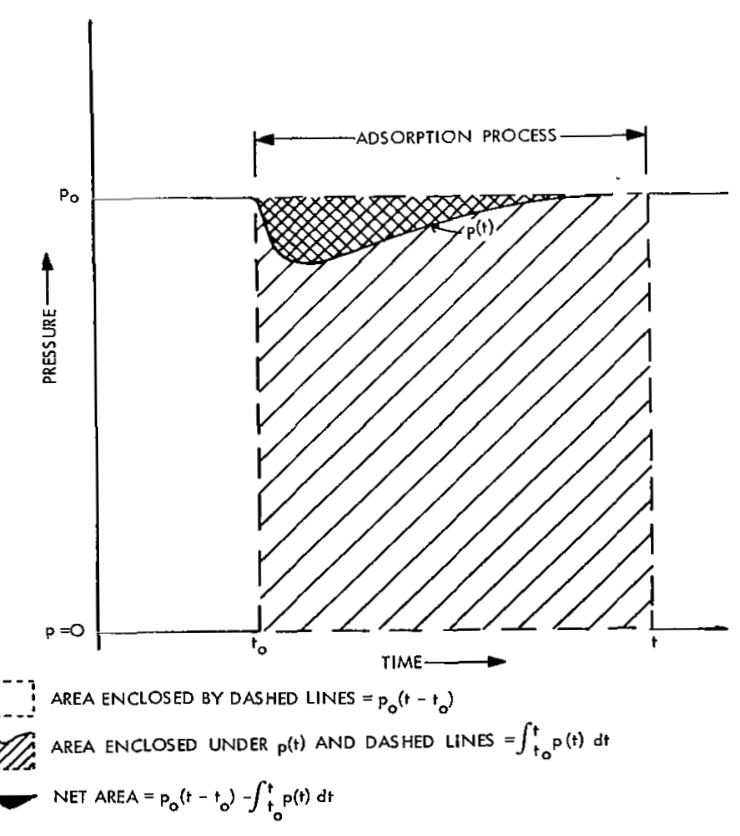

Figure 9.- Graphical determination of quantity in brackets in equation (19). material. The temperature was then measured and recorded. The temperature of the 347 stainless-steel cylinder was monitored during adsorption tests by two calibrated No. 36 gage copper-constantan wire thermocouples. (No. 36 gage wire was used to minimize the heat transfer into the adsorption cylinder.) One thermocouple was attached to the cylinder by tack-welding the junction (previously formed with silver solder) $6 \mathrm{~mm}$ below the cryogenic liquid level maintained during tests. The other thermocouple was unattached but was in proximity to the bottom of the cylinder. The cylinder did not acquire the temperature of the surrounding liquified gas instantaneously; therefore, an assumption is made here that the temperature at the bottom of the cylinder is the same as the 
cryogenic-liquid temperature. This arrangement permitted a mean temperature of the cylinder to be determined by averaging the bottom and top temperature measurements

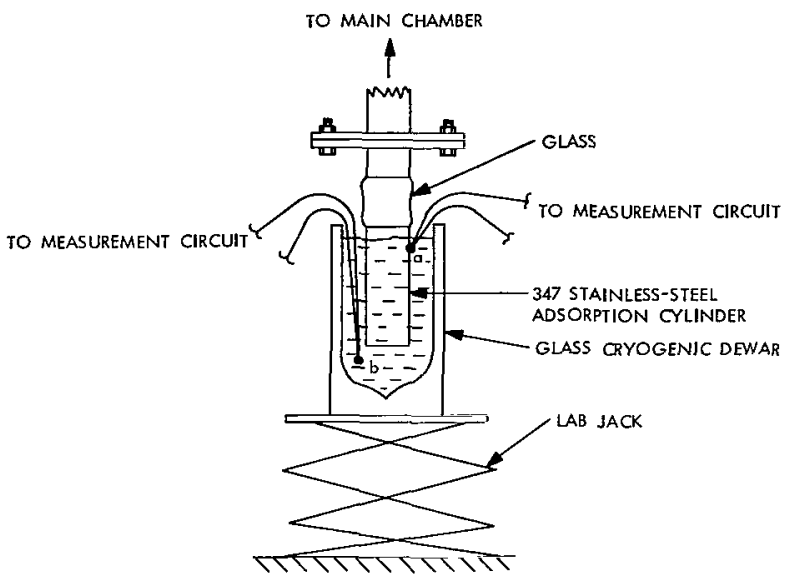

Figure 10.- Measurement of temperature during adsorption test. when the cylinder was immersed in the cryogenic liquid. The usual potentiometer and nanovoltmeter balance circuit was used for the measurements. The reference junction was immersed in liquid nitrogen. Figure 10 shows the arrangement of the thermocouples during the tests. The mean temperatures taken for the cylinder during the test with liquid nitrogen was $77.4^{\circ} \mathrm{K}$ and with liquid argon was $87.7^{\circ} \mathrm{K}$.

The pressure initially decreased as the gas molecules were adsorbed on the surface and then returned to its original value as equilibrium was approached. The IDVM was then turned to Stop and the number of volt-

seconds was recorded. This represented the numerical value of the terms in the brackets in equation (19). Multiplying by $\mathrm{S} / \mathrm{B}$ gives $\sigma$ or the number of molecules adsorbed.

After this step the IDVM was reset to zero and turned to Start. The cryogenic liquid was now removed from around the surface and the surface was allowed to return to room temperature naturally. As the temperature increased, the adsorbed molecules

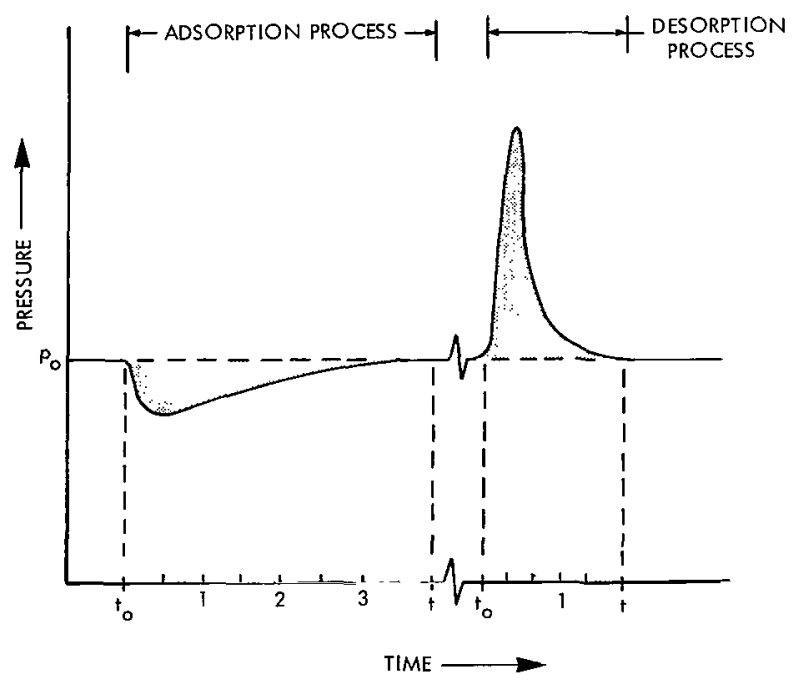

Figure 11.- Typical pressure time history of adsorption or desorption process. Shaded areas represent term in brackets in equation (19). desorbed. The IDVM then integrated the desorption process until no further change was noted (a return to equilibrium). The IDVM was then turned to Stop and the number of volt-seconds recorded. This represented the same difference in equation (19) as before but for the desorption process. The reversibility of the adsorption-desorption process was now checked by determining whether

$$
\sigma_{\text {adsorption }}=\sigma_{\text {desorption }}
$$

This relation was checked graphically as shown in figure 11. The time between $t_{0}$ and $t$ was approximately 5 minutes for the adsorption process and 2 minutes for the desorption process. The pressure-time 
areas were measured by using a planimeter and were found to be equal within 2 percent. All further data were then taken for desorption only.

The same procedure was repeated at successively higher equilibrium pressures to obtain the number of molecules adsorbed for each $\mathrm{p}_{\mathrm{o}}$. From a number of these points, the adsorption isotherm was thus constructed. Over the pressure range covered, the pressure above the adsorbed layer was determined by the ordinary thermal transpiration formula

$$
\frac{\mathrm{p}}{\mathrm{p}_{\mathrm{MC}}}=\sqrt{\frac{\mathrm{T}}{\mathrm{T}_{\mathrm{MC}}}}
$$

where $\mathrm{p}$ and $\mathrm{T}$ are the pressure and temperature of the gas above the adsorbed layer and $\mathrm{p}_{\mathrm{MC}}$ and $\mathrm{T}_{\mathrm{MC}}$ are the pressure and temperature of the gas in the main chamber (that is, that sensed by ion gage II). This entire process described was completed at two temperatures to obtain two isotherms. From these data, the heat of adsorption was obtained by using equation (13).

\section{RESULTS AND DISCUSSION}

\section{Surface Characterization}

Surface topography. - The photographs taken with the optical microscope at a magnification of $\times 2000$ are shown as figure 12 . The scratch marks from the polishing process are quite apparent, but no real information was obtained except to note that there are various imperfections and carbon grits which are not visible to the naked eye.

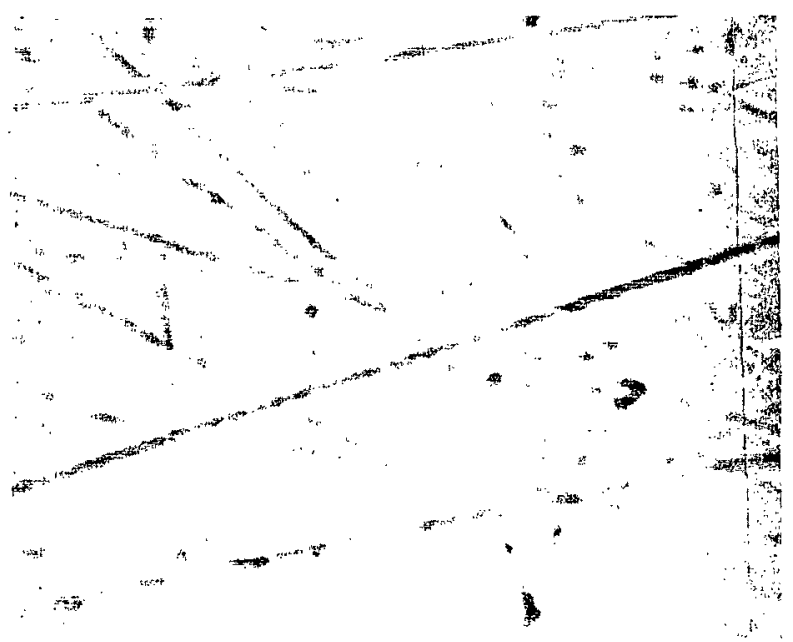

(a) Average surface.

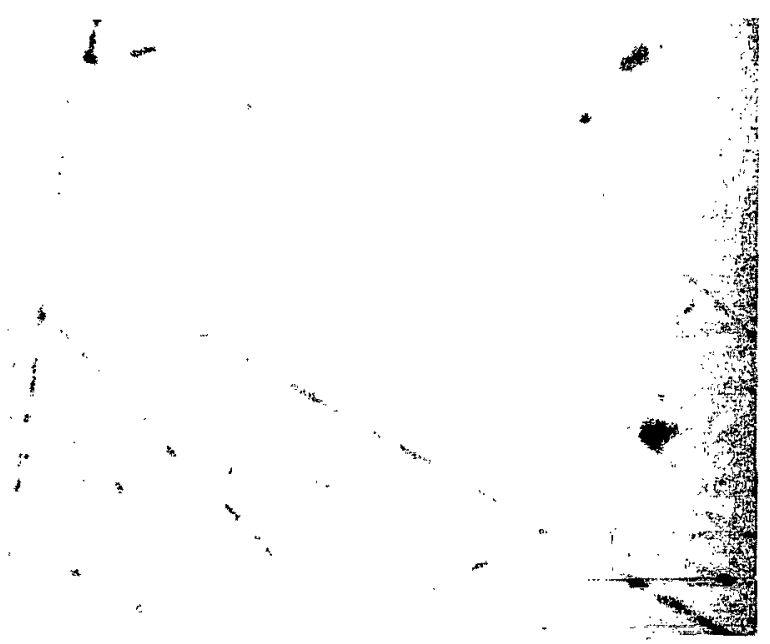

(b) Average surface.

Figure 12.- Photographs taken with an optical microscope. $\times 2000$. 


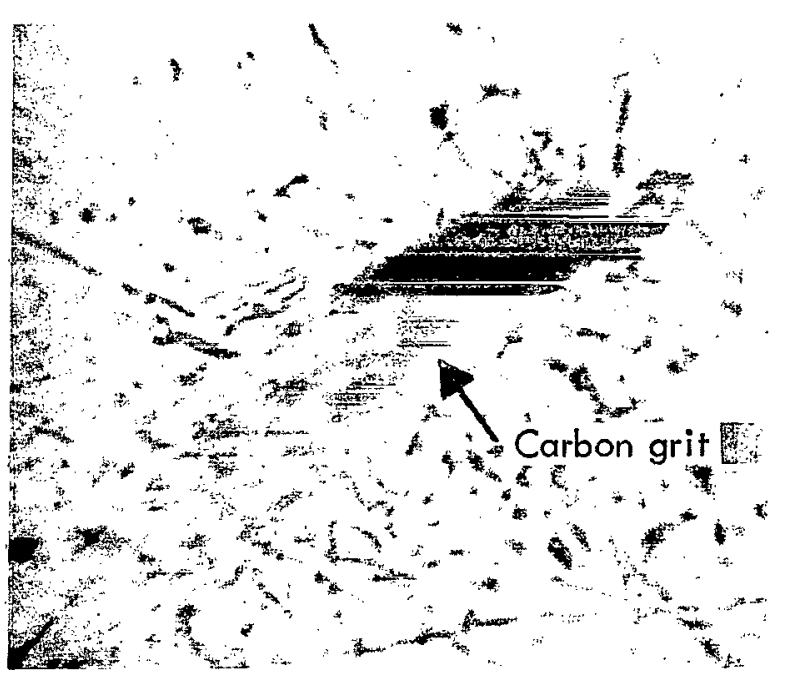

(c) Carbon grit.

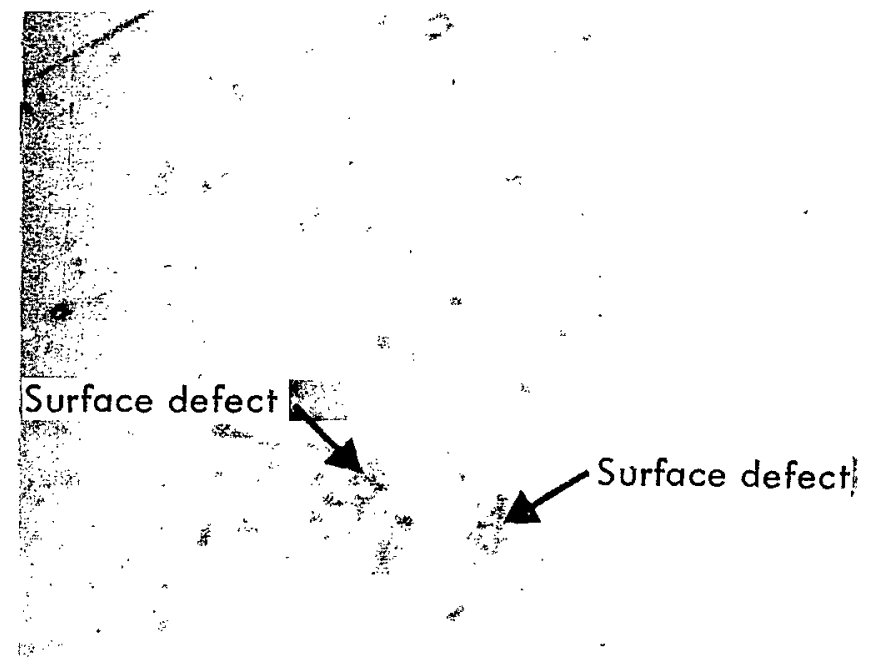

(d) Surface defects.

Figure 12.- Concluded.

Figure 13 represents the best photographs taken at the Goddard Space Flight Center with their scanning electron microscope. From a study of these photographs scratch marks as nar row as $300 \AA$ could be detected. In addition to the scratches, some dark spots were also noted. It was not determined whether the dark spots were from carbon grit or from carbon impurities that came from the steel.

In figure 14 a surface imperfection is shown in successive magnifications. The darker square in these photographs is due to vacuum-system diffusion-pump oil that has been carbonized by the electron beam. Figure 15 illustrates vacuum-fired samples used to study the grain boundaries. Various surface defects are also seen in these photographs. The average grain size appeared to be about $1 \times 10^{-3} \mathrm{~cm}$ in diameter. The polish marks are not apparent in these photographs. It is not known whether the high temperature tended to smooth out the surface or they were lost in replication. Since some of the surface imperfections are quite different, perhaps the first answer is the correct one.

Surface composition.- The unbaked and baked 347 stainless-steel samples were analyzed for surface composition in a microprobe solids mass spectrometer. The penetration depth in both tests was about 1 micron. Table I shows the relative weight percent (compared to iron) of all the major elements that were sputtered from the surface. The concentration in weight percent of each predominant element $x$ was determined from the following relation:

(Concentration of $x)\left(\right.$ Weight percent) $=\frac{\text { Peak intensity of } x}{\text { Peak intensity of Fe Sensitivity of } x}$ 


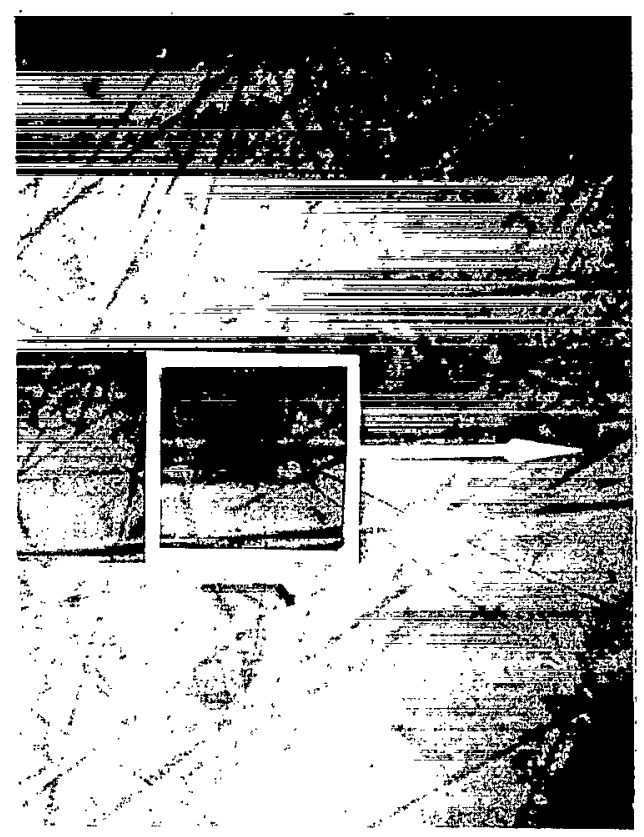

(a) $\times 1900$.

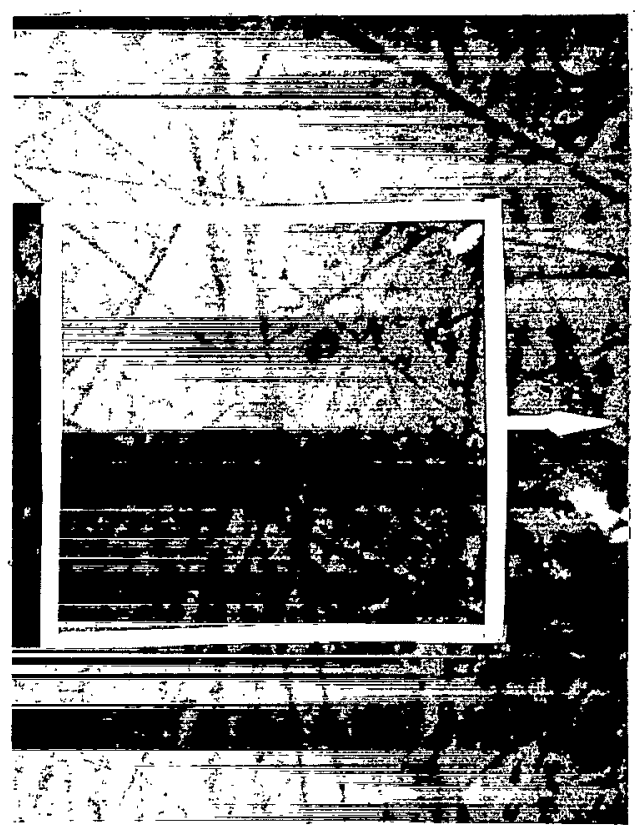

(c) $\times 2200$.

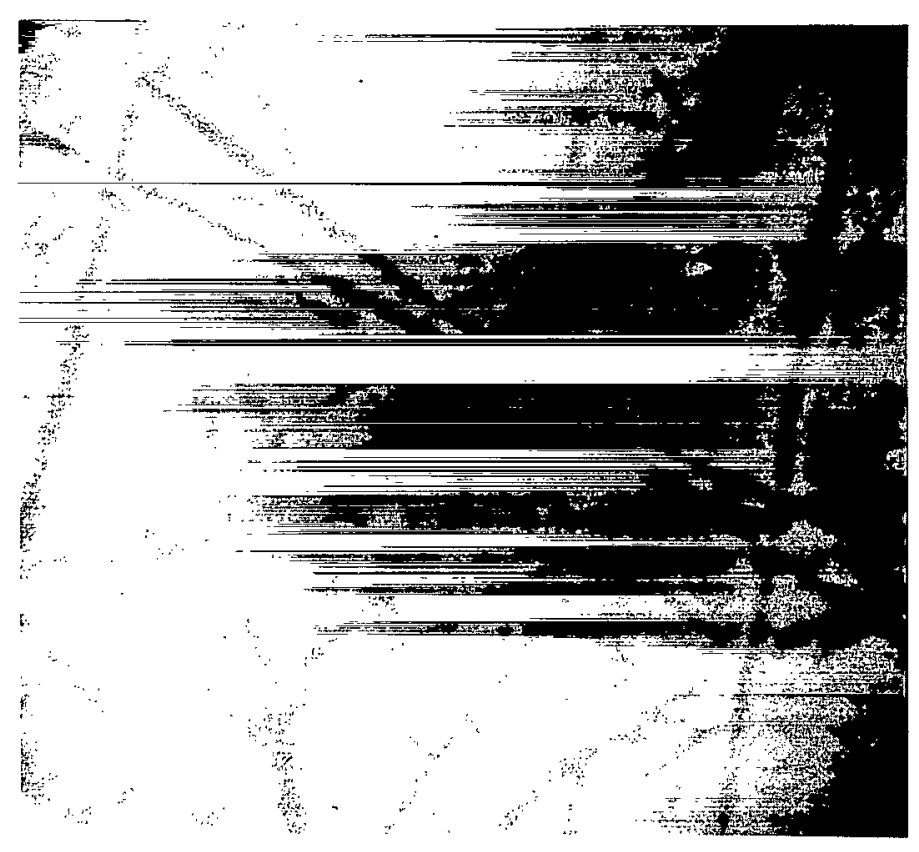

(b) $\times 9400$.

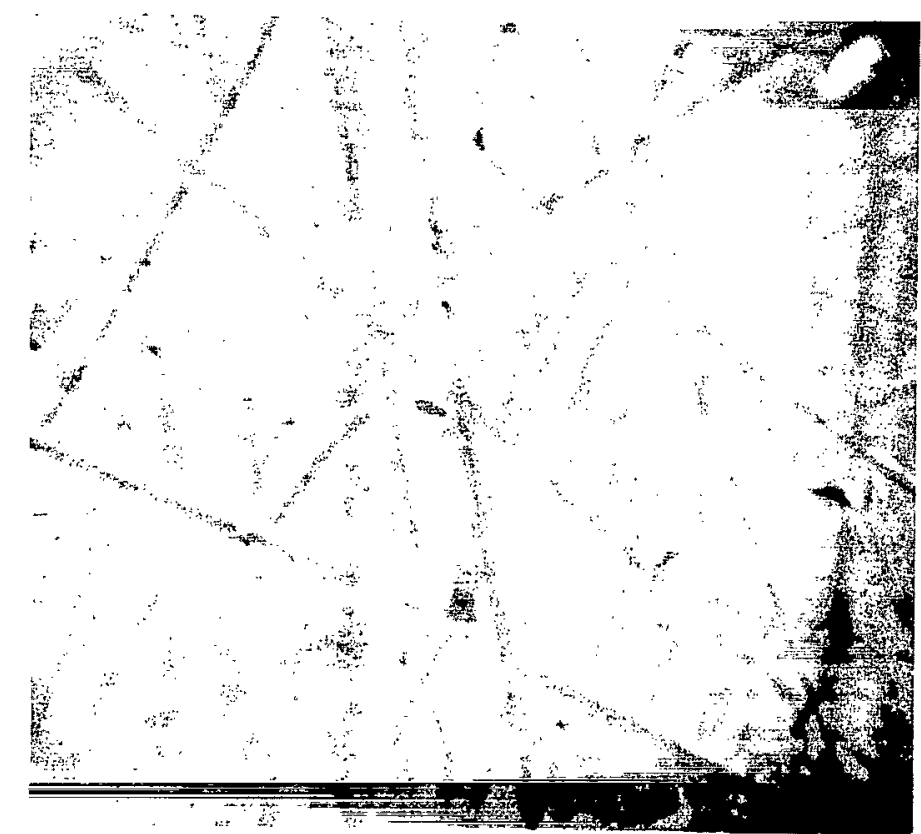

(d) $\times 4400$.

Figure 13.- Scanning electron micrographs. 


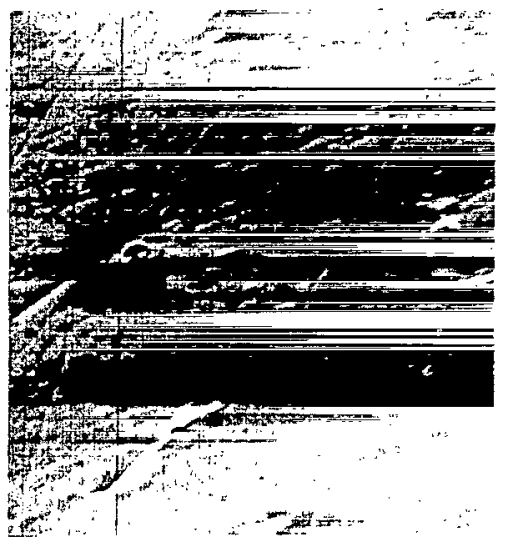

(a) $\times 2000$.

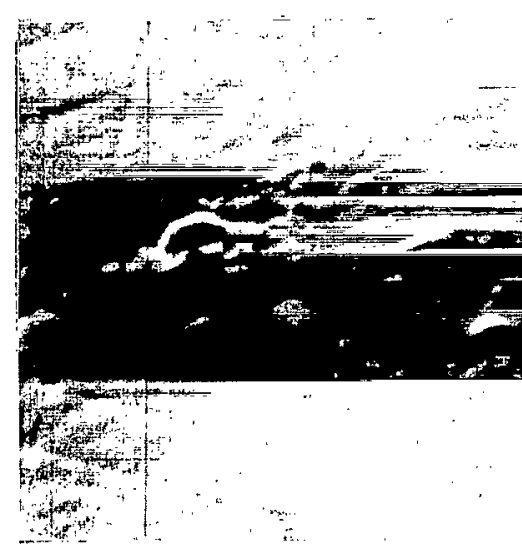

(b) $\times 5000$.

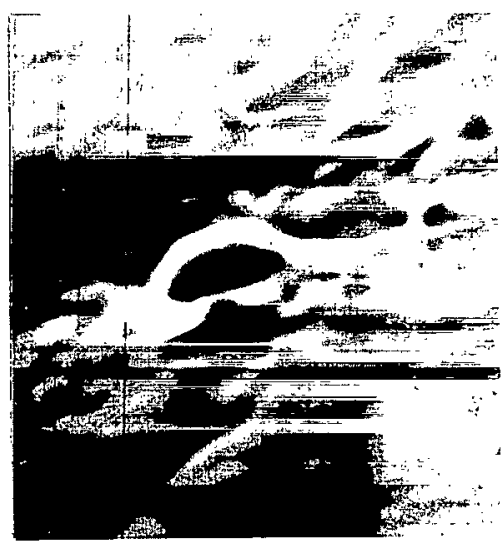

(c) $\times 7500$.

Figure 14.- Examples of surface defect shown in successive magnification. Photographs taken with scanning electron microscope at Langley Research Center.

\section{Grain \\ boundary}

Figure 15.- Vacuum-fired samples showing surface defects and grain boundaries. $\times 4200$. Photographs taken with transmission electron microscope. 
TABLE I. - COMPARISON OF ELEMENTAL CONCENTRATIONS IN BAKED AND UNBAKED 347 STAINLESS-STEEL SURFACES

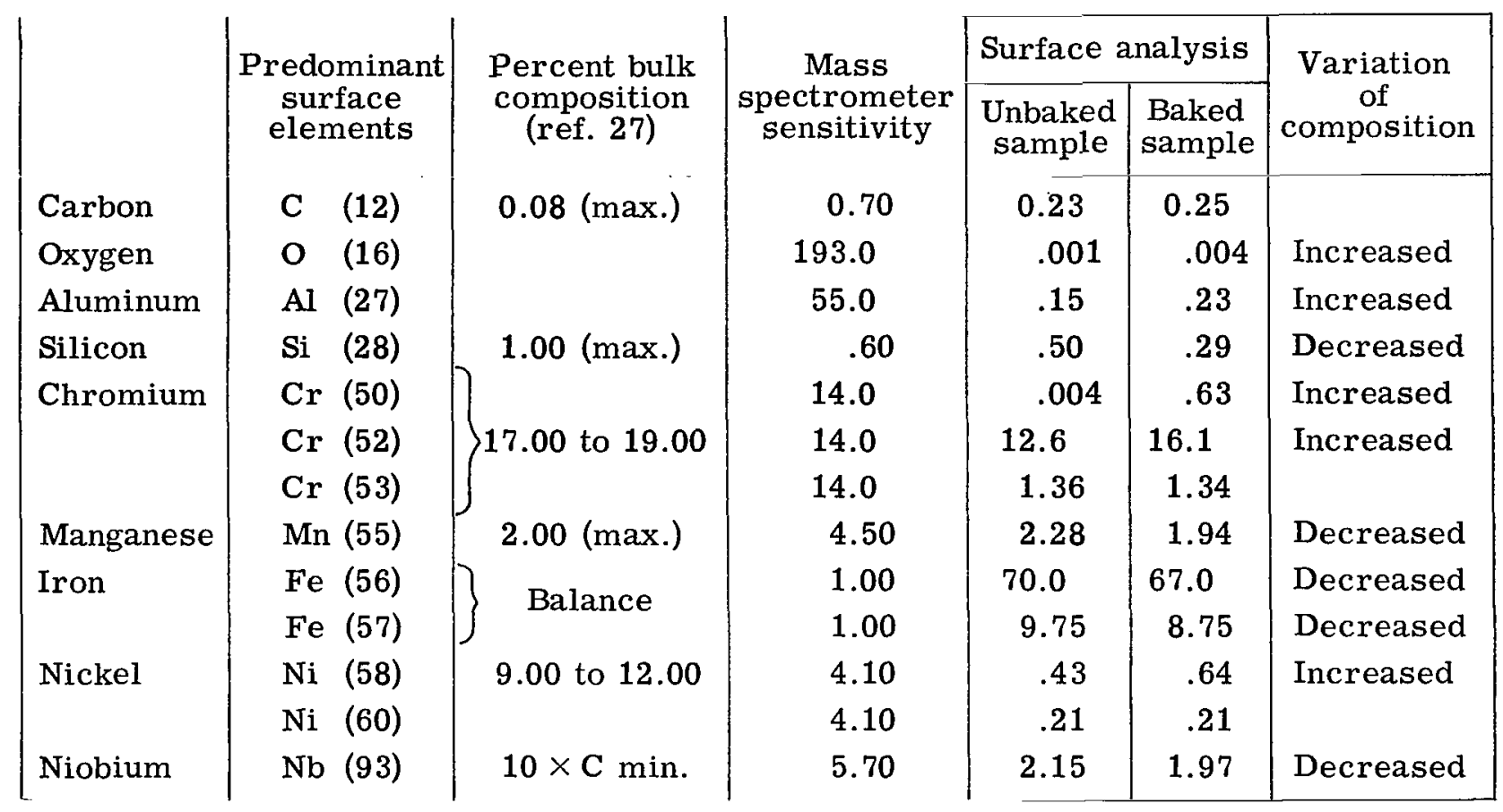

The published data (ref. 27) on the composition of the bulk of 347 stainless steel are recorded in the second column and the mass spectrometer sensitivities for the present analysis are recorded in the third column. The high percentage of carbon in the surface is probably due to the carbon grit buried in the surface during the polishing process.

As shown in figure 16, the oxygen profile measurement of the baked steel sample showed a fast rise in the initial phase of ion bombardment but fell to a low steady level for all subsequent scans. This result indicates that after sputtering off the oxide layer, the oxygen level had decreased to a steady value characteristic of the oxygen level in the bulk steel. The thickness of the oxide layer appeared to be about $400 \mathrm{~A}$ for the unbaked sample and about $800 \AA$ for the baked sample. From the data in table I, it is apparent that a significant diffusion of chromium to the surface with heating has taken place. It can be seen that the surface ( 1 to $2 \AA$ ) contains a great amount of chromium oxide. It is recognized that the chromium measurement was made at a depth of about $2500 \AA$ and that this is significantly below the surface layer. It should be emphasized that to assess the surface composition properly with this analysis, profile measurements at low penetration depths would have to be made for each predominant peak and would have to start each time on an unsputtered surface. The shorter the sputtering time the more representative of the actual surface the results are. 


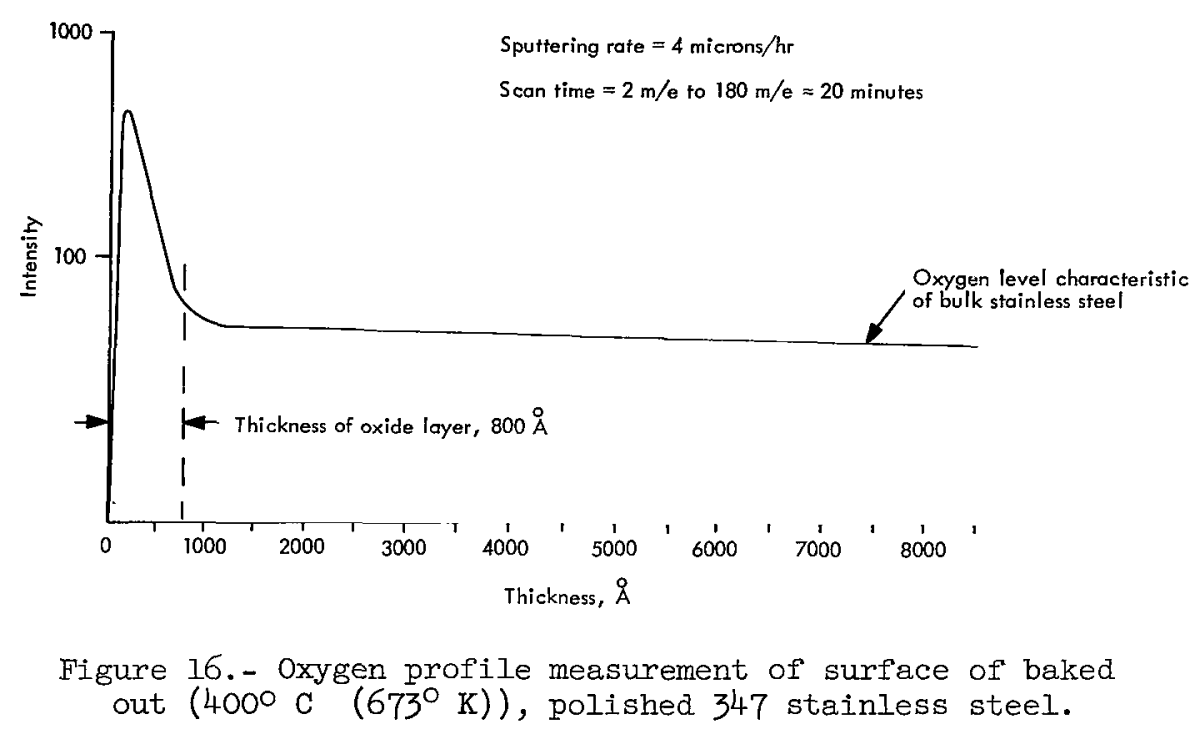

According to M. M. Goldberg of the Homer Research Laboratory, Bethlehem Steel Corporation, however, the analysis to a depth of 1 micron is fairly indicative of what the surface-layer oxide actually is. His previous work on unheated stainless steel has shown a chromium-enriched surface layer in the form of $\mathrm{Cr}_{2} \mathrm{O}_{3}$. Further examination of table I shows a decrease in iron percentage at the surface for the baked sample, probably due to diffusion of other elements from the bulk. Nickel, aluminum, and, in particular, chromium all increased in the surface composition layer. The small percentages of nickel in the surface layer as compared with the bulk is perplexing. From the present study, the predominant metals that make up the surface layer are Fe (56), Fe (57), Nb (93), Mn (55), $\mathrm{Cr}$ (53), and $\operatorname{Cr}$ (52). Goldberg suggests that most of the surface oxide of chromium is probably of the form $\mathrm{Cr}_{2} \mathrm{O}_{3}$. He also suggested that iron oxide in the forms $\mathrm{Fe}_{3} \mathrm{O}_{4}$ and $\mathrm{FeO}$ is also present. Since the chromium in the surface increased significantly in the 48-hour bakeout, the amount of $\mathrm{Cr}_{2} \mathrm{O}_{3}$ in the surface may be dependent on bakeout temperature and time.

\section{Adsorption Studies}

Nitrogen on pyrex glass. - The ultimate pressure attained after bakeout was $2 \times 10^{-10}$ torr $\left(\mathrm{H}_{2}\right)$ in the main chamber and $1 \times 10^{-9}$ torr $\left(\mathrm{H}_{2}\right)$ in the forechamber.

The pumping speed is very much a function of pressure. Although this is not abnormal, a variation in speed of 20 liters/second from approximately $1 \times 10^{-9}$ torr $\left(\mathrm{N}_{2}\right)$ to approximately $1 \times 10^{-7}\left(\mathrm{~N}_{2}\right)$ was not expected. Two points can be noted from this fact, however. First, it is advantageous to be able to ascertain the pumping speed while each data point was recorded since an assumption of a constant speed is apparently erroneous. 
Second, the vacuum system could be improved by utilizing a pump with a higher speed which has been "necked down" to obtain a conductance limitation and thereby to provide a constant pumping speed.

Examination of the data for nitrogen on pyrex glass indicated fair repeatability in the data points, but the pressure did not return to the original equilibrium value when the original pressure was $1 \times 10^{-9}$ torr. It is speculated that this problem was due to the background of hydrogen. At the lowest equilibrium pressure, $1 \times 10^{-9}$ torr, the quantity of hydrogen in the background was approximately 20 percent of the total molecular density. With increasing equilibrium pressure the quantity of hydrogen relative to the quantity of nitrogen decreased, and the pressure returned to the equilibrium pressure $p_{0}$. At a pressure of $3.5 \times 10^{-9}$ torr $\left(\mathrm{N}_{2}\right)$ the hydrogen was less than a 3-percent contribution to the total molecular density. The data beginning at this equilibrium pressure were plotted in figure 17.

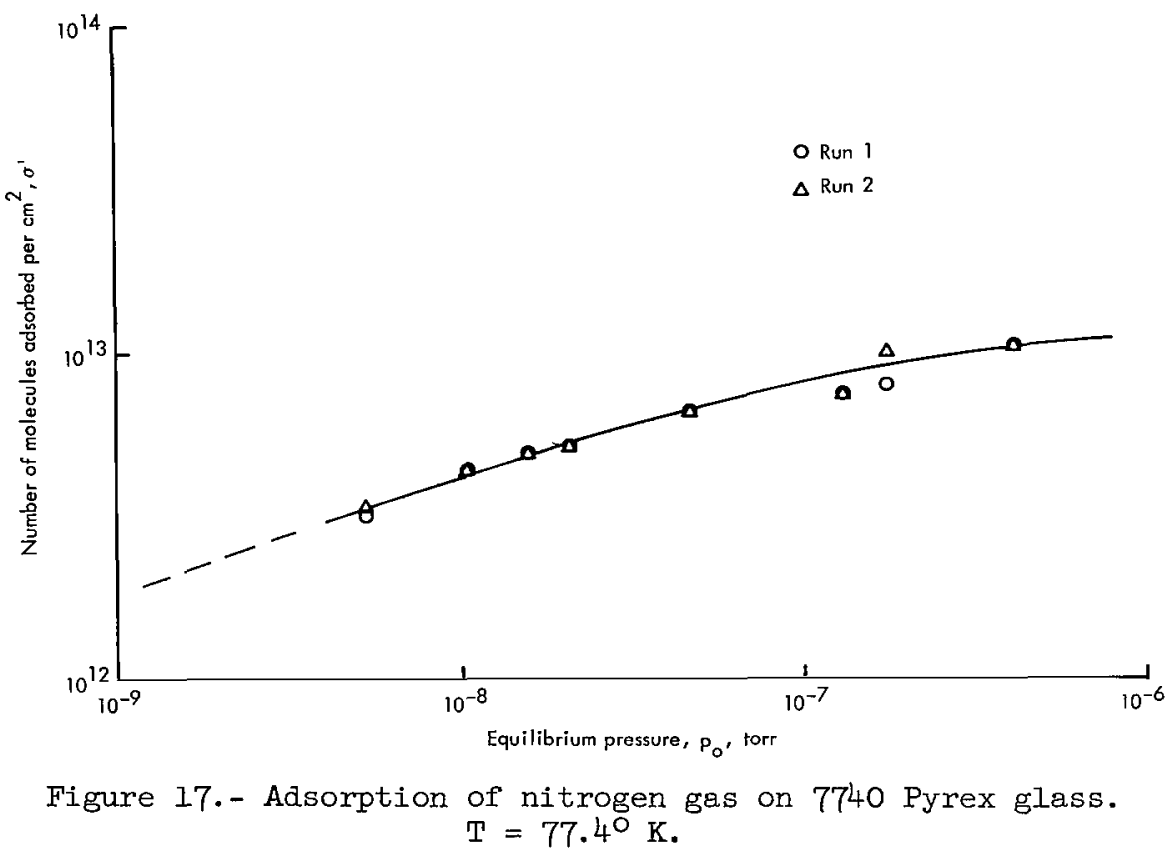

Comparison of the pyrex data presented in this paper with that of other researchers is shown in figure 18. The present data appear to be somewhat near the results of Hobson and Armstrong and Ricca and Medana but do not have a similar slope. It is noted, however, that the data of Hobson and Armstrong have a different slope than the data of Hobson. Two additional points of interest should be mentioned. Hobson (ref. 25) did not use a calibrated ion gage in his experiment, and with the gage structure that he used, the gage constant could vary from 15 torr $^{-1}$ to 33 torr $^{-1}$. Hobson and Armstrong calibrated their ion gage with a McLeod gage. The ion gage used in the present experiment was calibrated on 


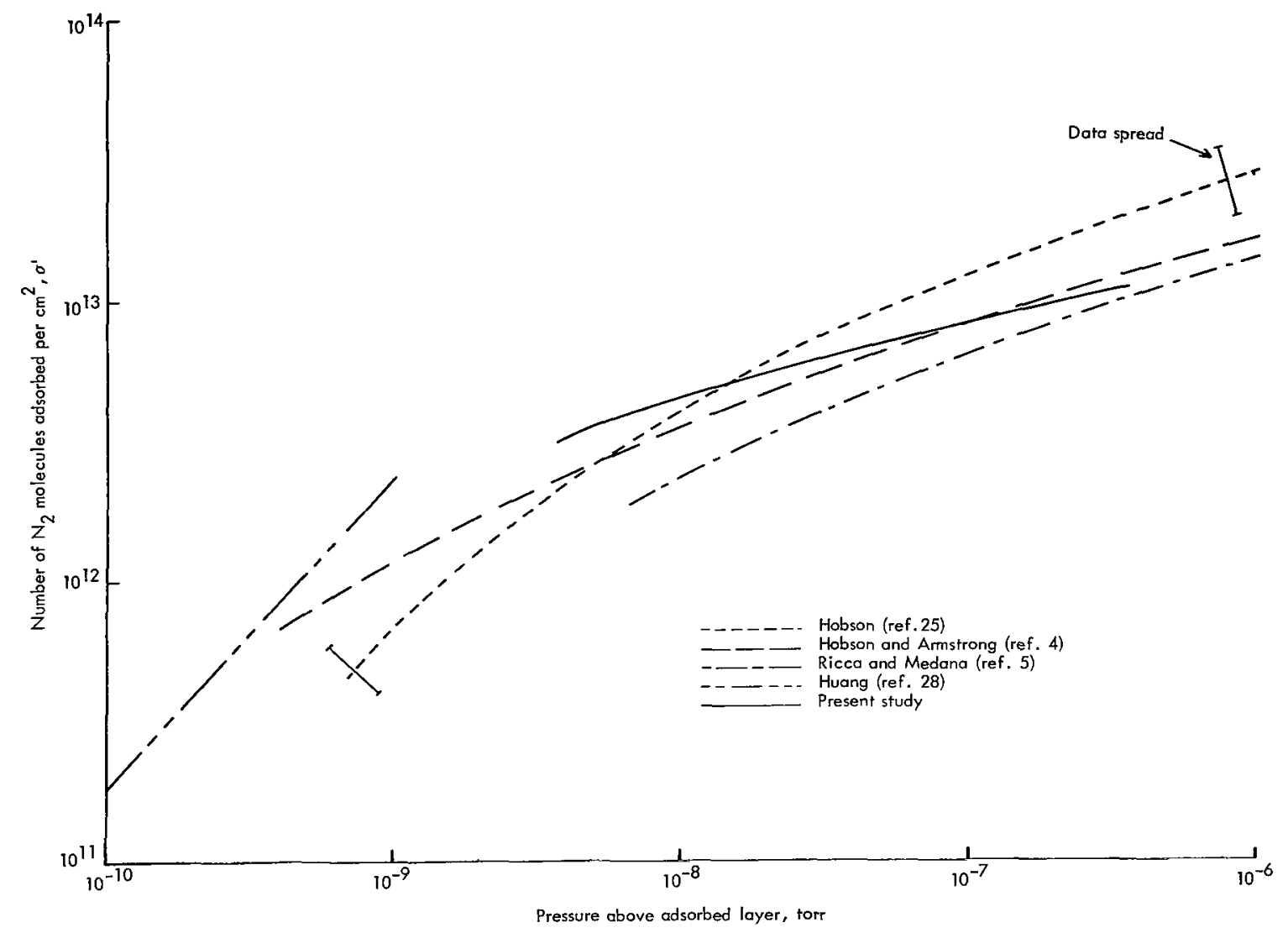

Figure 18.- Comparison of present data on adsorption of nitrogen gas on pyrex glass at $\mathrm{T}=77.4^{\circ} \mathrm{K}$ with other work.

an orifice system down to about $3 \times 10^{-9}$ torr $\left(\mathrm{N}_{2}\right)$. Ricca and Medana used a dynamic technique similar to the one used herein. Their data are lower than all other data presented. Huang's (ref. 28) theoretical prediction is also shown in figure 18. Figure 19 shows a least-squares fit of the Dubinin-Radushkevich equation for the slope indicated by the data points.

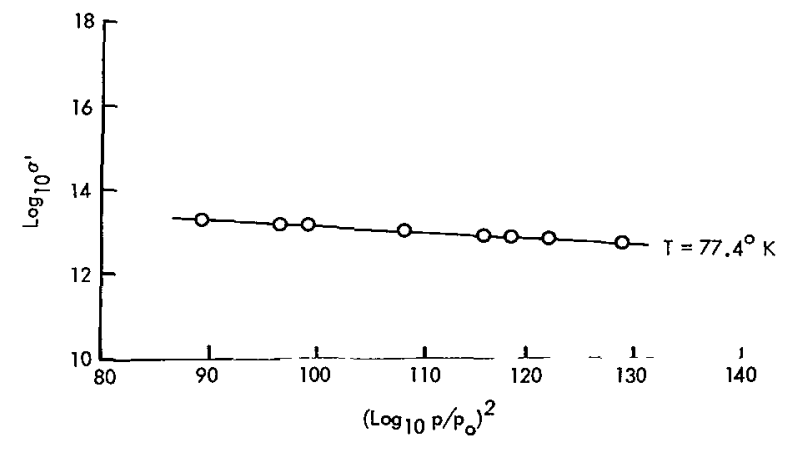

Figure 19.- Test of Dubinin-Radushkevich equation for nitrogen on pyrex. 
The Dubinin-Radushkevich equation is

$$
\log _{10} \sigma^{\prime}=\log _{10} \sigma_{m}^{\prime}-D \log _{10}\left(\frac{p}{p_{s}}\right)^{2}
$$

where
$\sigma^{\prime} \quad$ number of molecules adsorbed per $\mathrm{cm}^{2}$
$\sigma_{\mathrm{m}}^{\prime} \quad$ number of molecules adsorbed at monolayer coverage per $\mathrm{cm}^{2}$
D constant proportional to $(\mathrm{RT})^{2}$
p pressure above adsorbed layer
$\mathrm{p}_{\mathrm{S}} \quad$ saturation pressure corresponding to temperature

The constant $\mathrm{D}$ in equation (22) was determined to be about 0.013. Extrapolation of this least-squares-fitted straight line gives an intercept of 14.42 which yields a value for $\sigma_{\mathrm{m}}^{\prime}$ of $2.6 \times 10^{14}$ molecules $/ \mathrm{cm}^{2}$. This value is somewhat low compared with the expected $6.2 \times 10^{14}$ molecules $/ \mathrm{cm}^{2}$ (ref. 29) but the lack of extensive data could lead to an incorrect slope.

Nitrogen on 347 stainless steel. - Since a lower ultimate pressure $\left(2 \times 10^{-11}\right.$ torr $\left(\mathrm{H}_{2}\right)$ ) was obtained in the study of nitrogen on 347 stainless steel after bakeout than was obtained with the bakeout prior to the pyrex study, backfilling the system with nitrogen to $1 \times 10^{-9}$ torr $\left(\mathrm{N}_{2}\right)$ eliminated the problem of returning to the original equilibrium pressure as experienced previously. Comparison of the nitrogen partial pressure with the hydrogen partial pressure revealed less than a 2-percent contribution from the hydrogen.

The data points in figure 20 are represented by a visually fitted solid line that is intended to give the general shape of the curve. There appears to be more scatter in the data taken at $\mathrm{T}=87.7^{\circ} \mathrm{K}$ than at $\mathrm{T}=77.4^{\circ} \mathrm{K}$ but both isotherms seem to have essentially the same shape. Figure 21 represents the least-squares fit of the data to the DubininRadushkevich equation. The values for $\sigma^{\prime}$ used in the test of this equation were averages of the values collected on the two separate runs. Values of $D$ obtained from these plots were 0.032 for $T=87.7^{\circ} \mathrm{K}$ and 0.031 for $\mathrm{T}=77.4^{\circ} \mathrm{K}$; extrapolation of the straight lines gives ordinate intercepts of 16.6 and 16.4, respectively. These intercepts give values of $\sigma_{\mathrm{m}}^{\prime}=3.9 \times 10^{16}$ and $\sigma_{\mathrm{m}}^{\mathrm{r}}=2.5 \times 10^{16}$ for the number of molecules that would be adsorbed by monolayer coverage per $\mathrm{cm}^{2}$. If the surface were perfectly flat, a value of about $6.2 \times 10^{14}$ molecules $/ \mathrm{cm}^{2}$ should have resulted. These very high values of $\sigma_{\mathrm{m}}^{\prime}$ 


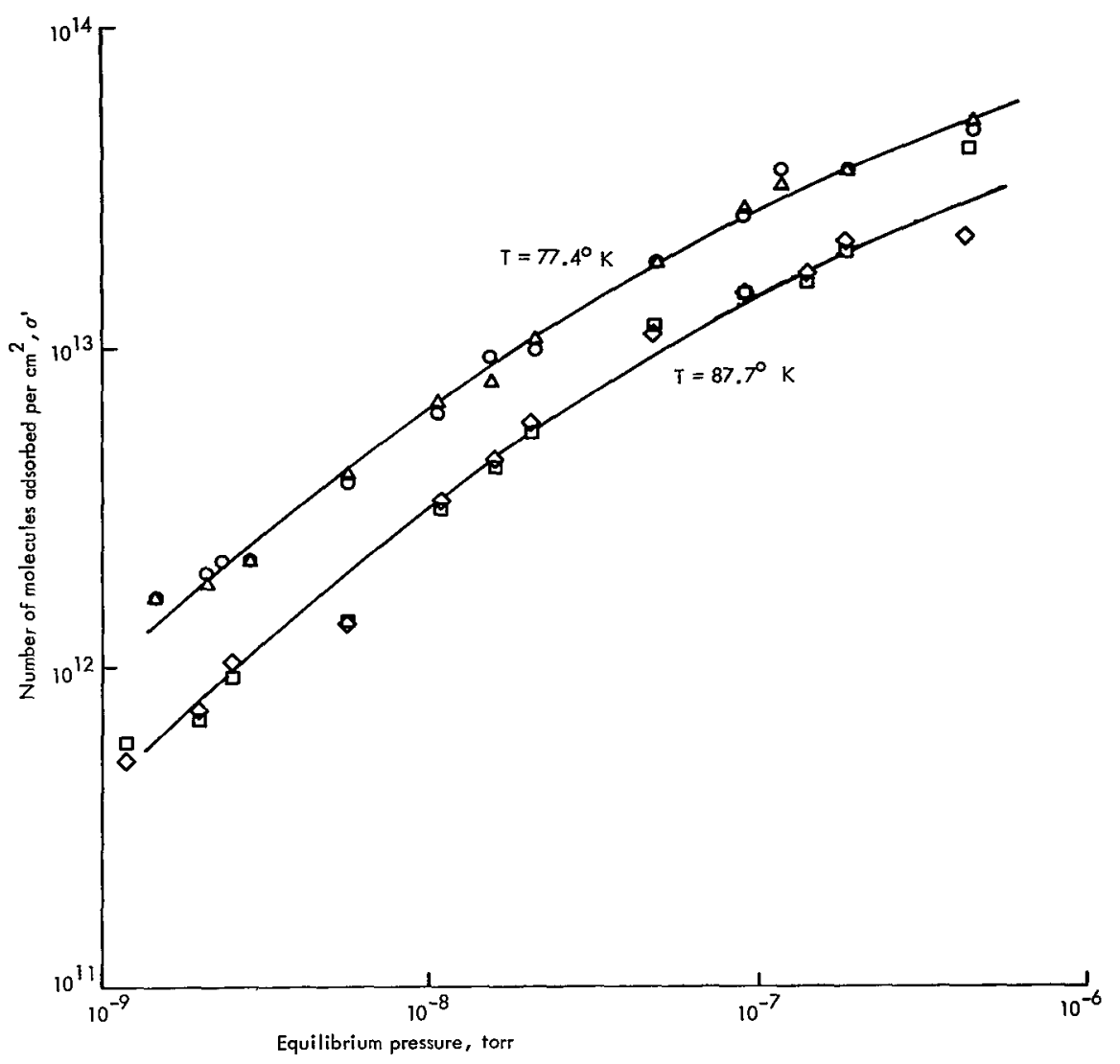

Figure 20.- Adsorption of nitrogen gas on polished 347 stainless steel. Isotherm temperatures, $77.4^{\circ} \mathrm{K}$ and $87.7^{\circ} \mathrm{K}$.
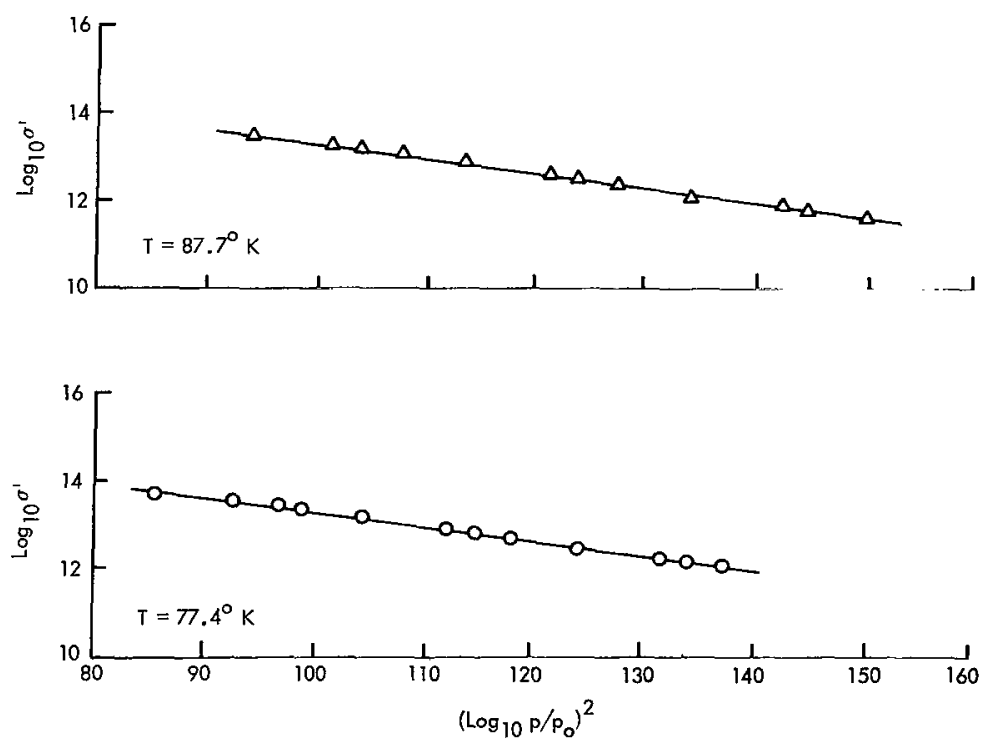

Figure 21.- Test of Dubinin-Radushkevich equation for nitrogen on 347 stainless steel. 
indicate a very large surface area, larger than might be explained by the many scratches. Perhaps the oxide on the surface has a porous character.

Pressure values taken from the two isotherms in figure 20 at the same number of molecules adsorbed (constant $\sigma^{\dagger}$ were inserted into the Clausius-Clapeyron analog equation (eq. 13)) and the isosteric heats of adsorption calculated (see appendix B). These data were then plotted against relative coverage $\theta$, where

$$
\theta=\frac{\sigma^{t}}{\sigma_{\mathrm{m}}^{\prime}}
$$

The value of $\sigma_{\mathrm{m}}^{\prime}$ used was $2.5 \times 10^{16}$. The resulting plot is shown in figure 22. The results of this experiment indicate a range of heats from 1.1 to $1.7 \mathrm{kcal} / \mathrm{mole}$ in the pressure range from $1 \times 10^{-9}$ to $1 \times 10^{-7}$ torr. The variation shown with relative coverage is indicative of a rough surface. This fact is further substantiated by the electron micrographs discussed previously (fig. 13). The roughness factor estimated from these results was about 40. Armbruster and Austin (ref. 7) did not elucidate their preparation of the metal surface before reduction but their results indicate the surface of chemically reduced, smooth cold-rolled steel to be as flat as glass.

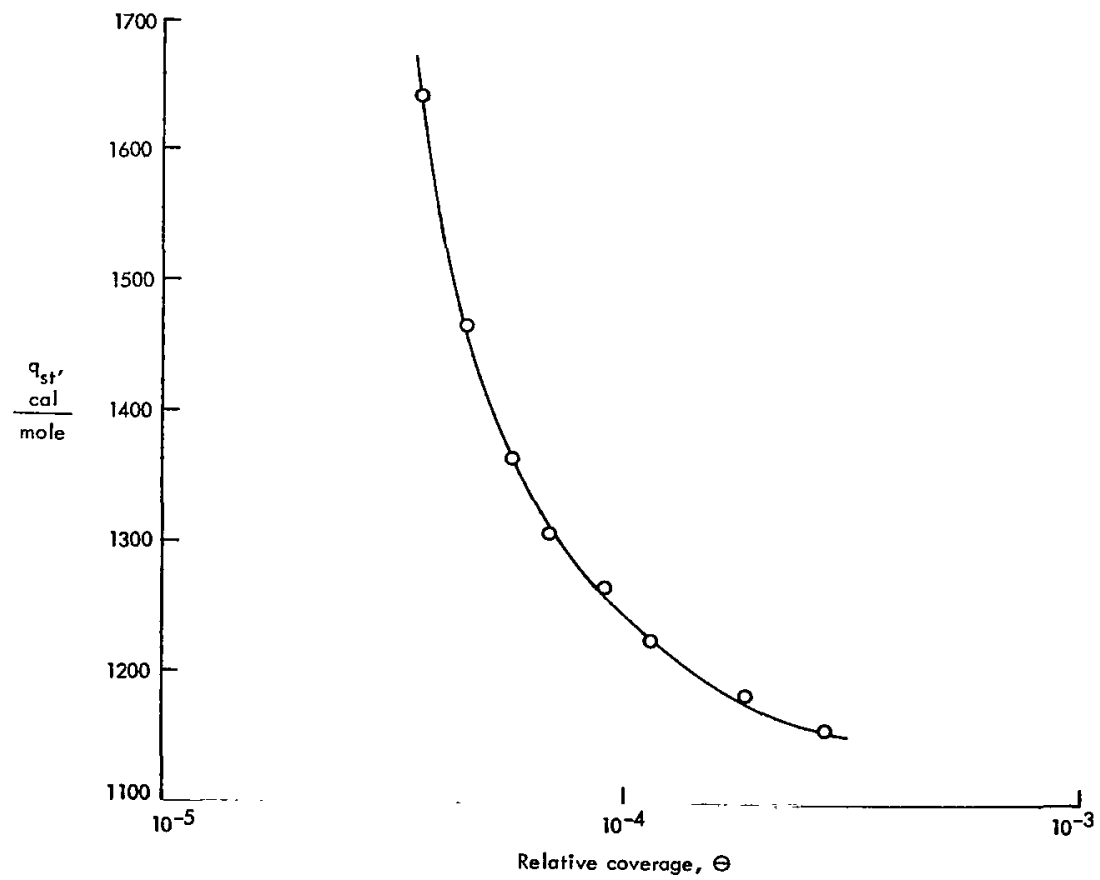

Figure 22.- Variation of isosteric heat of adsorption with relative coverage. 


\section{CONCLUSIONS}

A combined study of surface characterization and physical adsorption was performed on polished 347 stainless steel. The surface characterization was accomplished by topography and chemical composition studies. The physical adsorption measurements of nitrogen gas on stainless steel were made in the pressure range from $1 \times 10^{-9}$ to $1 \times 10^{-7}$ torr. The following conclusions were drawn from this investigation:

1. The ion microprobe mass spectrometer showed that in the surface layer of polished 347 stainless steel (1 micron thick) the concentration of chromium in the unbaked sample was less than that when the sample was baked to a temperature of $400^{\circ} \mathrm{C}\left(673^{\circ} \mathrm{K}\right)$ for over 48 hours.

2. The results from the physical adsorption of nitrogen on pyrex glass indicated that the vacuum system and dynamic technique used produced data comparable to the data of other researchers. The maximum possible error in the data obtained by using the present technique has been estimated to be 40 percent.

3. The surface of polished 347 stainless steel that has not been chemically reduced appears to be very rough. A roughness factor of approximately 40 was indicated.

4. Nitrogen was found to have a heat of physical adsorption on the polished steel surface in the range from 1.1 to $1.7 \mathrm{kcal} / \mathrm{mole}$ for the region of pressure from $1 \times 10^{-9}$. to $1 \times 10^{-7}$ torr.

5. The isotherm data, obtained at test temperatures of $87.7^{\circ}$ and $77.4^{\circ} \mathrm{K}$, appear to follow the Dubinin-Radushkevich equation.

6. The process of determining the numbers of molecules adsorbed can be accomplished electronically by use of the dynamic technique.

Langley Research Center,

National Aeronautics and Space Administration, Langley Station, Hampton, Va., February 18, 1970. 


\section{APPENDIX A}

\section{UNCERTAINTY IN THE ADSORPTION MEASUREMENT}

A determination of the uncertainty involved in the adsorption measurement can be made by use of equation (19), which is

$$
\sigma=\frac{S}{B}\left[p_{o}\left(t-t_{o}\right)-\int_{t_{o}}^{t} p(t) d t\right]
$$

Let the expression in brackets be represented by $\mathrm{Y}$ so that

$$
\sigma=\frac{\mathbf{S}}{\mathbf{B}} \mathbf{Y}
$$

Considering the variation in each quantity

$$
\sigma+\Delta \sigma=\frac{\mathrm{S}+\Delta \mathrm{S}}{\mathrm{B}+\Delta \mathrm{B}}(\mathrm{Y}+\Delta \mathrm{Y})
$$

or

$$
\sigma+\Delta \sigma=\frac{\mathrm{SY}+\mathrm{S} \Delta \mathrm{Y}+\mathrm{Y} \Delta \mathrm{S}}{\mathrm{B}+\Delta \mathrm{B}}
$$

where products of variations are neglected. Dividing by $\sigma$ yields

$$
1+\frac{\Delta \sigma}{\sigma}=\frac{1+\frac{\Delta Y}{Y}+\frac{\Delta S}{S}}{1+\frac{\Delta B}{B}}
$$

Multiplying through by $\left(1+\frac{\Delta B}{B}\right)$ gives

$$
1+\frac{\Delta \sigma}{\sigma}+\frac{\Delta B}{B}=1+\frac{\Delta Y}{Y}+\frac{\Delta S}{S}
$$

where the second-order terms are ignored. Thus

$$
\frac{\Delta \sigma}{\sigma}=\frac{\Delta \mathrm{Y}}{\mathrm{Y}}+\frac{\Delta \mathrm{S}}{\mathrm{S}}-\frac{\Delta \mathrm{B}}{\mathrm{B}}
$$

Each term on the right-hand side of equation (A1) is examined separately. 


\section{APPENDIX A - Continued}

The Pumping Speed S

From equations (18) and (15), the pumping speed $S$ is

$$
S=\frac{F p_{F C}}{p_{0}}
$$

The variation in pumping speed, determined in the same manner as $\frac{\Delta \sigma}{\sigma}$, is

$$
\frac{\Delta S}{S}=\frac{\Delta F}{F}+\frac{\Delta p_{F C}}{p_{F C}}+\frac{\Delta p_{o}}{p_{O}}
$$

Each pressure measurement is then found from equation (16) to be

$$
p=\frac{i^{+}}{i^{-} K}
$$

The uncertainty in the pressure measurement is

$$
\frac{\Delta p}{p}=\frac{\Delta i^{+}}{i^{+}}+\frac{\Delta i^{-}}{i^{-}}+\frac{\Delta K}{K}
$$

Therefore the pumping-speed uncertainty would be

$$
\frac{\Delta S}{S}=\frac{\Delta F}{F}+\frac{\Delta i_{F C}^{+}}{i_{F C}^{+}}+\frac{\Delta i_{F C}^{-}}{i_{F C}^{-}}+\frac{\Delta K_{F C}}{K_{F C}}+\frac{\Delta i_{O}^{+}}{i_{O}^{+}}+\frac{\Delta i_{O}^{-}}{i_{O}^{-}}+\frac{\Delta K_{O}}{K_{O}}
$$

\section{The Constant B}

The constant $\mathrm{B}$ is considered here as a possible source of error since it is proportional to the temperature which is measured by a thermocouple on the chamber wall and is expressed

$$
B=(\text { Constant })(T)
$$

and

$$
B+\Delta B=(\text { Constant })(T+\Delta T)
$$


Dividing this expression by $B$ yields

$$
1+\frac{\Delta B}{B}=1+\frac{\Delta T}{T}
$$

or

$$
\frac{\Delta \mathrm{B}}{\mathrm{B}}=\frac{\Delta \mathrm{T}}{\mathrm{T}}
$$

The Expression in Brackets Represented by $\mathrm{Y}$

In accordance with the procedure used for an adsorption measurement the first term in the brackets $p_{o}\left(t-t_{0}\right)$ was suppressed to zero and monitored by the integrating digital voltmeter. The accuracy of the IDVM on the voltage range used is 0.01 percent. This error is negligible compared with the measurement error in the second term $\int_{t_{0}}^{t} p(t) d t$.

$$
\mathrm{Y} \approx \int_{\mathrm{t}_{\mathrm{o}}}^{\mathrm{t}} \mathrm{p}(\mathrm{t}) \mathrm{dt}
$$

Since the maximum value of the integral is pt, let

$$
\mathrm{Y}=\mathrm{pt}
$$

then

$$
\frac{\Delta Y}{Y}=\frac{\Delta p}{p}+\frac{\Delta t}{t}=\frac{\Delta i^{+}}{i^{+}}+\frac{\Delta i^{-}}{i^{-}}+\frac{\Delta K}{K}+\frac{\Delta t}{t}
$$

Substituting equations (A2), (A3), and (A4) in equation (A1) yields

$$
\begin{aligned}
\frac{\Delta \sigma}{\sigma}= & \frac{\Delta \mathrm{i}^{+}}{\mathrm{i}^{+}}+\frac{\Delta \mathrm{i}^{-}}{\mathrm{i}^{-}}+\frac{\Delta \mathrm{K}}{\mathrm{K}}+\frac{\Delta \mathrm{t}}{\mathrm{t}}-\frac{\Delta \mathrm{T}}{\mathrm{T}}+\frac{\Delta \mathrm{F}}{\mathrm{F}}+\frac{\Delta \mathrm{i}_{\mathrm{FC}}^{+}}{\mathrm{i}_{\mathrm{FC}}^{+}}+\frac{\Delta \mathrm{i}_{\mathrm{FC}}^{-}}{\mathrm{i}_{\mathrm{FC}}^{-}} \\
& +\frac{\Delta \mathrm{K}_{\mathrm{FC}}}{\mathrm{K}_{\mathrm{FC}}}+\frac{\Delta \mathrm{i}_{\mathrm{O}}^{+}}{\mathrm{i}_{\mathrm{O}}^{+}}+\frac{\Delta \mathrm{i}_{\mathrm{o}}^{-}}{\mathrm{i}_{\mathrm{O}}^{-}}+\frac{\Delta \mathrm{K}_{\mathrm{O}}}{\mathrm{K}}
\end{aligned}
$$




\section{APPENDIX A - Concluded}

The errors for each term in equation (A5) are as follows:

$$
\begin{aligned}
& \frac{\Delta \mathrm{i}^{+}}{\mathrm{i}^{+}}=\frac{\Delta \mathrm{i}^{-}}{\mathrm{i}^{-}}=\frac{\Delta \mathrm{i}_{\mathrm{FC}}^{+}}{\mathrm{i}_{\mathrm{FC}}^{+}}=\frac{\Delta \mathrm{i}_{\mathrm{FC}}^{-}}{\mathrm{i}_{\mathrm{FC}}^{-}}=\frac{\Delta \mathrm{i}_{\mathrm{O}}^{+}}{\mathrm{i}_{\mathrm{O}}^{+}}=\frac{\Delta \mathrm{i}_{\mathrm{O}}^{-}}{\mathrm{i}_{\mathrm{O}}^{-}}=1.5 \text { percent } \\
& \frac{\Delta \mathrm{K}}{\mathrm{K}}=\frac{\Delta \mathrm{K}_{\mathrm{O}}}{\mathrm{K}_{\mathrm{O}}}=8.5 \text { percent } \\
& \frac{\mathrm{K}_{\mathrm{FC}}}{\mathrm{t}}=10.5 \text { percent } \\
& \frac{\Delta \mathrm{T}}{\mathrm{T}}=0.2 \text { percent } \\
& \frac{\Delta \mathrm{F}}{\mathrm{F}}=3.0 \text { percent }
\end{aligned}
$$

Summing these values gives the maximum total uncertainty in the adsorption measurement, which is

$$
\frac{\Delta \sigma}{\sigma}=39.4 \text { percent }
$$




\section{APPENDIX B \\ DERIVATION OF THE CLAUSIUS-CLAPEYRON ANALOG EQUATION FOR ADSORPTION}

For a system where the unadsorbed gas phase is in equilibrium with the adsorbed gas phase, the chemical potential may be written

$$
\left.\begin{array}{l}
\mu_{\mathrm{g}}=\mathrm{f}(\mathrm{T}, \mathrm{p}) \\
\mu_{\mathrm{s}}=\mathrm{f}\left(\mathrm{T}, \mathrm{p}, \sigma_{\mathrm{S}}\right) \\
\mu_{\mathrm{g}}=\mu_{\mathrm{s}}
\end{array}\right\}
$$

where

$\mu_{\mathrm{g}} \quad$ chemical potential of unadsorbed gas

$\mu_{\mathrm{S}} \quad$ chemical potential of adsorbed gas

$\sigma_{\mathrm{S}} \quad$ number of moles of adsorbed gas

and it follows that

$$
\begin{gathered}
\mathrm{d} \mu_{\mathrm{g}}=\frac{\partial \mu_{\mathrm{g}}}{\partial \mathrm{T}} \mathrm{dT}+\frac{\partial \mu_{\mathrm{g}}}{\partial \mathrm{p}} \mathrm{dp} \\
\mathrm{d} \mu_{\mathrm{S}}=\frac{\partial \mu_{\mathrm{S}}}{\partial \mathrm{T}} \mathrm{dT}+\frac{\partial \mu_{\mathbf{S}}}{\partial \mathrm{p}} \mathrm{dp}+\frac{\partial \mu_{\mathbf{S}}}{\partial \sigma_{\mathrm{S}}} \mathrm{d} \sigma_{\mathbf{S}}
\end{gathered}
$$

The change in internal energy for the unadsorbed gas $U_{g}$ at constant temperature and pressure is

$$
d U_{g}=T d s_{g}-p d V_{g}
$$

and for the adsorbed gas is

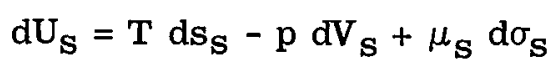




\section{APPENDIX B - Continued}

If the Gibbs free energy is defined as

$$
\mathrm{G}=\mathrm{U}-\mathrm{Ts}+\mathrm{pV}
$$

then

$$
d_{g}=-s_{g} d T+V_{g} d p
$$

and

$$
\mathrm{dG}_{\mathrm{S}}=-\mathrm{s} d \mathrm{~T}+\mathrm{V}_{\mathrm{S}} \mathrm{dp}+\mu_{\mathrm{S}} \mathrm{d} \sigma_{\mathrm{S}}
$$

Considering the exact differential, equation (B8)

$$
-\frac{\partial \mathbf{S}_{\mathbf{S}}}{\partial \sigma_{\mathbf{S}}}=\frac{\partial \mu_{\mathbf{S}}}{\partial \mathrm{T}}=-\overline{\mathbf{S}}_{\mathbf{S}}
$$

and

$$
\frac{\partial \mathbf{V}_{\mathbf{s}}}{\partial \sigma_{\mathbf{S}}}=\frac{\partial \mu_{\mathbf{s}}}{\partial \mathbf{p}}=\overline{\mathbf{V}}_{\mathbf{s}}
$$

where $\overline{\mathbf{s}}_{\mathbf{S}}$ and $\overline{\mathrm{V}}_{\mathbf{S}}$ are differential entropy and volume, respectively, of the adsorbed gas. Equation (B3) can then be written

$$
d \mu_{S}=-\bar{s}_{S} d T+\bar{V}_{S} d p+\frac{\partial \mu_{S}}{\partial \sigma_{S}} d \sigma_{S}
$$

Now by definition

$$
\mathrm{G}=\mu \mathrm{n}
$$

where $\mathrm{n}$ is the number of moles of a substance. Then

$$
\mathrm{dG}_{\mathrm{g}}=\mathrm{d} \mu_{\mathrm{g}} \mathrm{n}_{\mathrm{g}}+\mu_{\mathrm{g}} \mathrm{dn} \mathrm{n}_{\mathrm{g}}
$$

For a constant number of moles in the gas phase $n_{\mathrm{g}}$ and in the adsorbed state $\sigma_{\mathrm{S}}$ the situation required that

$$
\mathrm{dn}_{\mathrm{g}}=\mathrm{d} \sigma_{\mathrm{s}}=0
$$




\section{APPENDIX B - Continued}

Combining equations (B7), (B11), and (B12) yields

$$
d \mu_{g}=-\frac{s_{g}}{n_{g}} d T+\frac{v_{g}}{n_{g}} d p
$$

or

$$
\mathrm{d} \mu_{\mathrm{g}}=-\hat{\mathrm{s}}_{\mathrm{g}} \mathrm{dT}+\hat{\mathrm{V}}_{\mathrm{g}} \mathrm{dp}
$$

where $\hat{s}_{g}$ and $\hat{v}_{g}$ are the molar entropy and molar volume, respectively, of the unadsorbed gas.

Considering equations (B1)

$$
\mathrm{d} \mu_{\mathrm{g}}=\mathrm{d} \mu_{\mathrm{s}}
$$

or

$$
-\hat{s}_{g} d T_{\sigma_{s}}+\hat{V}_{g} d p_{\sigma_{s}}=-\bar{s}_{s} d T_{\sigma_{s}}+\bar{V}_{s} d p_{\sigma_{S}}
$$

so that

$$
\left(\frac{\partial p}{\partial T}\right)_{\sigma_{s}}=\frac{\hat{s}_{g}-\overline{\mathbf{s}}_{\mathbf{s}}}{\hat{\mathbf{V}}_{\mathrm{g}}-\overline{\mathbf{V}}_{\mathbf{s}}}
$$

By definition, $T\left(\hat{s}_{\mathrm{g}}-\overline{\mathbf{s}}_{\mathrm{s}}\right)$ is the isosteric heat of adsorption $\mathrm{q}_{\mathrm{st}}$. Thus

$$
\left(\frac{\partial p}{\partial T}\right)_{\sigma_{s}}=\frac{q_{s t}}{\left(\hat{\mathbf{v}}_{g}-\overline{\mathbf{V}}_{s}\right) T}
$$

By the assumption that $\hat{\mathrm{V}}_{\mathrm{g}} \gg \overline{\mathrm{V}}_{\mathrm{s}}$ and $\mathrm{p} \hat{\mathrm{V}}_{\mathrm{g}}=\mathrm{RT}$, equation (B15) becomes

$$
\left(\frac{\partial p}{\partial T}\right)_{\sigma_{S}}=\frac{p q_{s t}}{R T^{2}}
$$

or

$$
\left(\frac{\partial \ln p}{\partial T}\right)_{\sigma_{S}}=\frac{q_{s t}}{R T^{2}}
$$




\section{APPENDIX B - Concluded}

which is the Clausius-Clapeyron analog (ref. 23). Integration of this equation between two equilibrium temperatures for a constant $\sigma_{\mathrm{S}}$ yields

$$
\mathrm{q}_{\mathrm{st}}=\mathrm{R} \ln \frac{\mathrm{p}_{2}}{\mathrm{p}_{1}}\left(\frac{\mathrm{T}_{2} \mathrm{~T}_{1}}{\mathrm{~T}_{2}-\mathrm{T}_{1}}\right)
$$

where $p_{1}$ and $p_{2}$ are the equilibrium pressures for a particular $\sigma_{\mathrm{S}}$ and $\mathrm{T}_{1}$ and $\mathrm{T}_{2}$ are the corresponding temperatures. Thus, by measuring the slope of $\Delta$ In $\mathrm{p}$ with $\Delta \frac{1}{\mathrm{~T}}$, one can determine $\mathrm{q}_{\text {st }}$, which is a measure of the binding energy between the adsorbed atom or molecule and the surface. 


\section{APPENDIX C \\ DERIVATION OF THE EQUATION TO DETERMINE THE NUMBER OF ADSORBED MOLECULES $\sigma$}

Consider the main chamber in which the test surface is located, having the configuration shown in the following sketch:

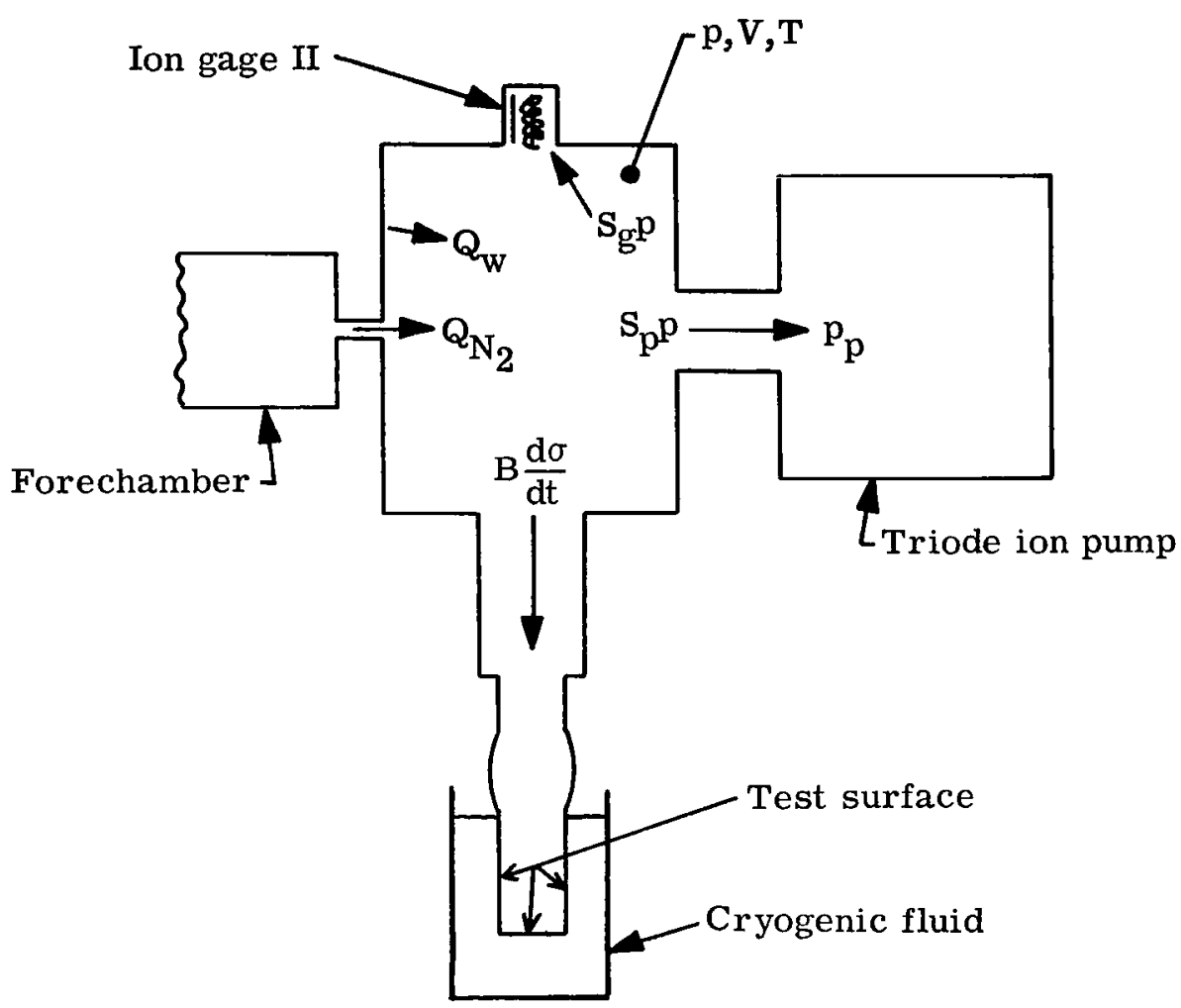

for which

p pressure in chamber

$\mathrm{p}_{\mathrm{p}} \quad$ pressure in triode ion pump

$p_{0} \quad$ equilibrium pressure established

V chamber volume

T temperature of gas 


\section{APPENDIX C - Continued}

$\begin{array}{ll}Q_{\mathrm{N}_{2}} & \text { nitrogen (test gas) gas flow } \\ \mathbf{Q}_{\mathrm{w}} & \text { gas flow from walls and all exposed surfaces } \\ \mathbf{Q} & \text { total gas flow, } \mathrm{Q}_{\mathrm{N}_{2}}+\mathrm{Q}_{\mathrm{w}} \\ \mathrm{S}_{\mathrm{p}} & \text { triode ion pumping speed } \\ \mathrm{S}_{\mathrm{g}} & \text { ionization-gage pumping speed } \\ \mathrm{S} & \text { effective pumping speed } \\ \sigma & \text { number of molecules adsorbed on test surface } \\ \mathrm{B} & \text { constant proportional to kT }\end{array}$

Then the equation for equilibrium molecular balance within the main chamber must be

Rate of change of the number = Rate at which molecules - Rate at which molecules of molecules in $\mathrm{V} \quad$ enter $\mathrm{V}$ leave $\mathrm{V}$

and the main-chamber dynamic equation ${ }^{3}$ is

$$
\frac{d(p V)}{d t}=Q-S_{p}\left(p-p_{p}\right) \pm \frac{B d \sigma}{d t}-S_{g}\left(p-p_{g}\right)
$$

where the + and - associated with the third term in the right-hand side of the equation refer to desorption and adsorption, respectively. For a constant volume and the usual assumption $p \gg p_{p}$ and since $s_{p} \gg S_{g}, S_{p} \approx S$, and

$$
\frac{V d p}{d t}=Q-S p \pm \frac{B d p}{d t}
$$

3 A temperature consideration is ignored in this equation since the metal adsorption cylinder equilibrates to test temperature so rapidly. 


\section{APPENDIX C - Concluded}

Multiplying both sides of equation (C3) by dt and integrating from $t_{o}$ to $t$, from $p_{o}$ to $\mathrm{p}$, and from 0 to $\sigma$, yields

$$
\int_{p_{0}}^{p} V d p=Q \int_{t_{0}}^{t} d t-s \int_{t_{0}}^{t} p(t) d t \pm B \int_{0}^{\sigma} d \sigma
$$

where

$t_{0} \quad$ time when adsorption or desorption begins

$\mathrm{p}_{\mathrm{o}} \quad$ established equilibrium pressure in main chamber

Solving equation (C4) gives

$$
\pm \sigma(t)=\frac{V}{B}\left(p-p_{o}\right)-\frac{Q}{B}\left(t-t_{o}\right)+\frac{S}{B} \int_{t_{o}}^{t} p(t) d t
$$

If a long enough time elapses after the test surface is cooled or warmed, equilibrium will return and $\mathrm{p}-\mathrm{p}_{\mathrm{O}}$, thus

$$
\pm \sigma(t)=-\frac{Q}{B}\left(t-t_{o}\right)+\frac{S}{B} \int_{t_{o}}^{t} p(t) d t
$$

In a normal dynamic process an equilibrium pressure $\mathrm{p}_{\mathrm{o}}$ is established by bleeding the test gas into the forechamber which, in turn, bleeds through the molecular leak into the main chamber at a flow rate $Q$. The surface to be studied is lowered to a predetermined temperature by immersion in a cryogenic liquid. The adsorption then begins to take place. The surface acts like a small pump and the pressure decreases slightly. As equilibrium is reached, the number of molecules adsorbed becomes a constant, the surface no longer acts like a pump, and the pressure returns to $p_{O}$. The adsorption process begins at $t_{o}$ when the temperature is lowered and ends at some time $t$ when equilibrium is reached. The variation in pressure over the time $t_{0} \rightarrow t$ is accounted for by the integral

$$
\int_{t_{0}}^{t} p(t) d t
$$

This integral is the only unknown on the right-hand side of equation (C6). Thus $\sigma$, the number of molecules adsorbed on the test surface, can be determined by finding the value of the integral experimentally. (The total pumping speed of the system is determined by

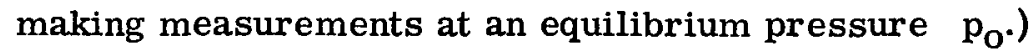




\section{REFERENCES}

1. Caruso, S. V.; and Looney, W. C.: A Study of the Outgassing and Evaporation Products of Some Materials Upon Exposure to Reduced Pressure. MTP-P\&VE-M-62-7, NASA George C. Marshall Space Flight Center, 1962.

2. Calder, R.; and Lewin, G.: Reduction of Stainless Steel Outgassing in Ultra-High Vacuum. 1966 13th National Vacuum Symposium of the American Vacuum Society, W. J. Lange, ed., Amer. Vacuum Soc., c.1966, p. 107.

3. Degras, D. A.; Schram, A.; Lux, B.; and Petermann, L. A.: Desorption of NS 22S Stainless Steel by Flash-Filament Technique in Ultra High Vacuum. 1961 Transactions of the Eighth Vacuum Symposium and Second International Congress, Vol. 1, Luther E. Preuss, ed., Macmillan Co., 1962, pp. 177-185.

4. Hobson, J. P.; and Armstrong, R. A.: A Study of Physical Adsorption at Very Low Pressures Using Ultrahigh Vacuum Techniques. J. Phys. Chem., vol. 67, no. 10, Oct. 1963, pp. 2000-2008.

5. Ricca, Franco; and Medana, Riccardo: Adsorbimento Fisico di $\mathrm{N}_{2}$ e di $\mathrm{CH}_{4}$ su Vetro, a Pressioni Molto Basse (Physical Adsorption of $\mathrm{N}_{2}$ and $\mathrm{CH}_{4}$ on Glass at Very Low Pressures). Ric. Sci. Rend. Sez. A, vol. 4, no. 5, 1964, pp. 617-630.

6. Hansen, N.: Physikalische Adsorption bei tiefen Drucken und geringen Belegungen (Physical Adsorption at Low Pressures and Coverages). Vakuum-Tech., Jahrg. 11, Heft 3, Apr. 1962, pp. 70-77.

7. Armbruster, Marion H.; and Austin, J. B.: The Adsorption of Gases on Smooth Surfaces of Steel. J. Amer. Chem. Soc., vol. 66, no. 2, Feb. 10, 1944, pp. 159-171.

8. Armbruster, Marion H.: The Sorption of Water Vapor at Low Pressure on the Surface of Some Cold-Rolled Steels at $20^{\circ}$. J. Amer. Chem. Soc., vol. 68, no. 7, July 1946, pp. $1342-1347$.

9. Wightman, James P.; and Mugler, John P., Jr.: The Adsorption of Argon, Helium and Nitrogen on Stainless Steel at Room Temperature in the Pressure Range $10^{-8}$ to $10^{-7}$ Torr. Paper presented at 152nd National Meeting, Amer. Chem. Soc. (New York, N.Y.), Sept. 11-16, 1966.

10. Ehrlich, Gert: Molecular Processes in Adsorption on Metals. 1961 Transactions of the Eighth Vacuum Symposium and Second International Congress, Vol. 1, Luther E. Preuss, ed., Macmillan Co., 1962, pp. 126-145.

11. Farnsworth, H. E.: Preparation and Characterization of Atomically Clean Surfaces for Investigation in Ultra-High Vacuum. Clean Surfaces: Their Preparation and Characterization for Interfacial Studies, Marcel Dekker, Inc., 1969. 
12. Bradford, James McLure, Jr.: A Study of the Adhesion of Nickel. Ph. D. Thesis, North Carolina State Univ. at Raleigh, 1968.

13. Bryant, P. J.; Taylor, L. H.; and Gutshall, P. L.: Cleavage Studies of the Lamellar Solids in Various Gas Environments. 1963 Transactions of the Tenth National Vacuum Symposium of the American Vacuum Society, George H. Bancroft, ed., Macmillan Co., c.1963, pp. 21-26.

14. Adamson, Arthur W.: Physical Adsorption - A Tool in the Study of the Frontiers of Matter. J. Chem. Educ., vol. 44, no. 12, Dec. 1967, pp. 710-716.

15. Adamson, Arthur W.: Physical Chemistry of Surfaces. Second ed., Interscience Publ., c.1967.

16. London, F.: Zur Theorie und Systematik der Molekularkräfte (Theory and System of Molecular Forces). Z. Phys., vol. 63, nos. 3-4, July 1930, pp. 245-279.

17. Margenau, H.; and Pollard, W. G.: The Forces Between Neutral Molecules and Metallic Surfaces. Phys. Rev., Second ser., vol. 60, no. 2, July 15, 1941, pp. 128-134.

18. Lennard-Jones, J. E.: Processes of Adsorption and Diffusion on Solid Surfaces. Trans. Faraday Soc., vol. 28, Apr. 1932, pp. 333-359.

19. Young, D. M.; and Crowell, A. D.: Physical Adsorption of Gases. Butterworths, 1962.

20. Clausing, P:: Flow of Gas at Very Low Pressure Through Tubes of Various Lengths. Ann. Phys., Bd. 12, Heft 8, Mar. 10, 1932, pp. 961-989.

21. Helmer, John C.: Solution of Clausing's Integral Equation for Molecular Flow. J. Vacuum Sci. Technol., vol. 4, no. 6, Nov./Dec. 1967, pp. 360-363.

22. Bayard, Robert T.; and Alpert, Daniel: Extension of the Low Pressure Range of the Ionization Gauge. Rev. Sci. Instrum., vol. 21, no. 6, June 1950, pp. 571-572.

23. Redhead, P. A.: Modulated Bayard-Alpert Gauge. Rev. Sci. Instrum., vol. 31, no. 3, Mar. 1960, pp. 343-344.

24. Hayward, W. H.; and Jepsen, R. L.: A Simple High Vacuum Gauge Calibration System. 1962 Transactions of the Ninth National Vacuum Symposium of the American Vacuum Society, George H. Bancroft, ed., Macmillan Co., c.1962, pp. 459-462.

25. Hobson, J. P.: First Adsorbed Layer of Nitrogen on Pyrex at $77.4^{\circ} \mathrm{K}$. Can. J. Phys., vol. 37, no. 10, Oct. 1959, pp. 1105-1113.

26. Ricca, Franco; Bellardo, Aldo; and Medana, Riccardo: Physical Adsorption of CO on Pyrex Glass at Very Low Pressures. Ric. Sci., vol. 36, no. 6, June 1966, pp. 460-465.

27. Anon.: Stainless Steel Handbook. Allegheny Ludlum Steel Corp., c.1956, pp. 21-23. 
28. Huang, A. B.: An Analysis of Physical Adsorption Isotherms in Ultrahigh-Vacuum Range. J. Vacuum Sci. Technol., vol. 2, no. 1, Jan./Feb. 1965, pp. 6-11.

29. Flood, E. Alison, ed.: The Solid-Gas Interface. Vol. 1, Marcel Dekker, Inc., 1967, pp. $476-477$. 


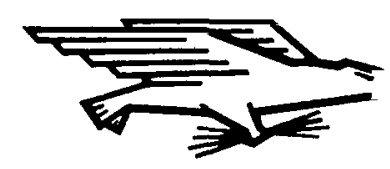

POSTAGE AND FEES PAID NATIONAL AERONAUTICS Ai SPACE ADMINISTRATION

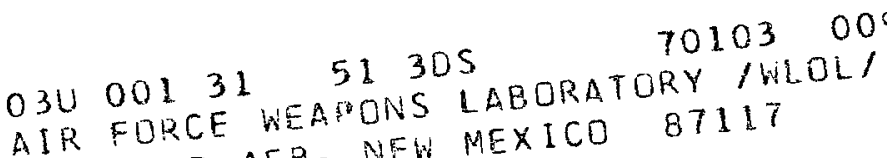

AIR FORCE WEAONS LABORATORY

ATT E LOU BOAMAN CHIEF TECH LIBRARY

POSTMASTER:

If Undeliverable (Secrion 158 Postal Manual) Do Not Returı

"The acronautical and space activities of the United States shall be conducted so as to contribute . . to the expansion of buman knotuledge of phenomena in the atmosphere and space. The Administration shall provide for the widest practicable and appropriate dissemination of information concerning its activities and the results thereof."

- National Aeronautics and Space ACt of 1958

\section{NASA SCIENTIFIC AND TECHNICAL PUBLICATIONS}

TECHNICAL REPORTS: Scientific and technical information considered important, complete, and a lasting contribution to existing knowledge.

TECHNICAL NOTES: Information less broad in scope but nevertheless of importance as a contribution to existing knowledge.

TECHNICAL MEMORANDUMS:

Information receiving limited distribution because of preliminary data, security classification, or other reasons.

CONTRACTOR REPORTS: Scientific and technical information generated under a NASA contract or grant and considered an important contribution to existing knowledge.
TECHNICAL TRANSLATIONS: Information published in a foreign language considered to merit NASA distribution in English.

SPECIAL PUBLICATIONS: Information derived from or of value to NASA activities. Publications include conference proceedings, monographs, data compilations, handbooks, sourcebooks, and special bibliographies.

\section{TECHNOLOGY UTILIZATION}

PUBLICATIONS: Information on technology used by NASA that may be of particular interest in commercial and other non-aerospace applications. Publications include Tech Briefs, Technology Utilization Reports and Notes, and Technology Surveys.

Details on the availability of these publications may be obtained from:

\section{SCIENTIFIC AND TECHNICAL INFORMATION DIVISION}

NATIONAL AERONAUTICS AND SPACE ADMINISTRATION

Washington, D.C. 20546 